\title{
Observations and Simulations of the Mesoscale Environment in TOMACS Urban Heavy Rain Events
}

\author{
Naoko SEINO \\ Meteorological Research Institute, Tsukuba, Japan \\ Ryoko ODA \\ Chiba Institute of Technology, Narashino, Japan \\ Hirofumi SUGAWARA \\ National Defense Academy, Yokosuka, Japan \\ and \\ Toshinori AOYAGI \\ Japan Meteorological Agency, Tokyo, Japan
}

(Manuscript received 6 December 2016, in final form 13 January 2018)

\begin{abstract}
During the intensive observation period (IOP) of the Tokyo Metropolitan Area Convection Study for Extreme Weather Resilient Cities (TOMACS) in the summer months of 2011-2013, the atmospheric environment of several heavy rainfalls was observed by radiosonde soundings in the Tokyo metropolitan area. We investigated the formation and development processes of an extremely developed thunderstorm (Case 1 on August 26, 2011) and a moderately developed thunderstorm (Case 2 on July 18, 2013) during the TOMACS IOP by utilizing radiosonde sounding data. Compared with Case 2, Case 1 featured a lower level of free convection and a deeper layer of easterly flow in the mesoscale environment of the severe storm. We performed numerical simulations to investigate the formation processes of the convective systems in the two cases by using the nonhydrostatic model of the Japan Meteorological Agency incorporating the square prism urban canopy scheme. Model results fairly represented the spatial distribution and amounts of the rainfall in both cases. In Case 1, the formation of a distinct convergence zone between easterly and southerly flows was the likely trigger of active convective systems around Tokyo. To further examine the urban impact on precipitation, we performed two comparative simulations: one using realistic current urban surface conditions (CRNT experiment) and the other using less-urbanized surface conditions (LURB experiment). The CRNT experiment yielded more rainfall than the LURB experiment in the central urban area. It appears that the higher temperatures caused by urbanization can lead to increased rainfall in Tokyo by intensifying convergence and ascending motion.
\end{abstract}

Keywords heavy rain; TOMACS; radiosonde observation; urban impact on precipitation; Tokyo

Corresponding author: Naoko Seino, Meteorological Re-

search Institute, 1-1 Naganime, Tsukuba 305-0052, Japan

E-mail: nseino@mri-jma.go.jp

J-stage Advance Published Date: 17 February 2018

(C) The Author(s) 2018. This is an open access article published by the Meteorological Society of Japan under a Creative Commons Attribution 4.0 International (CC BY 4.0) license (http://creativecommons.org/license/by/4.0). 


\section{Introduction}

Urban areas have an inherent vulnerability to severe weather. In the Tokyo metropolitan area, extremely heavy rainfall sometimes causes flash flooding and associated damages. A better understanding of the mesoscale and microscale processes of the severe weather, as well as improved forecast and use of sophisticated warning systems, is required for disaster preparedness for extreme weather events.

Statistical approaches have been used in some studies to examine environmental conditions for the convective system formation in Japan. Hirahara and Mizuno (2000) investigated the relation between the occurrence of heavy rainfalls and various environmental parameters and showed that the K-index (KI) can be a good indicator of the heavy rain occurrence in summer. Chuda and Niino (2005) studied the climatological seasonal variations of atmospheric environmental parameters that are widely used to characterize the environment of mesoscale convective systems by using 10 years' worth of routine radiosonde data from 18 stations in Japan. More specifically, Nomura and Takemi (2011) investigated the environmental stability for afternoon rain events over the Kanto Plain in summer and showed that colder temperatures at middle levels and higher humidity at low to middle levels are favorable conditions for the development of stronger rains in the afternoon.

Case studies of severe storms in the Tokyo area have also been conducted. Seko et al. (2007) investigated the evolution of thunderstorms in the Nerima heavy rainfall event on July 21,1999 , and revealed the detailed airflow structure of the mesoscale convective systems. Kawabata et al. (2007) numerically studied the formation mechanism of the heavy rainfall in the same event and showed that a surface convergence line of horizontal winds was made of southerly sea breeze and northeasterly winds and was enhanced around Nerima.

Surface wind patterns preceding short-time heavy rainfall in Tokyo have been extensively studied by Fujibe et al. (2002). They examined 16 heavy rain cases in the Tokyo ward area and revealed that the coexistence of easterly and southerly flows, referred to as the E-S wind pattern, is one of the favorable conditions for local heavy rainfall in the district in midsummer. The above mentioned Nerima heavy rainfall event is a typical example of a severe storm that developed in the E-S wind pattern.

Radar observations have also provided insights into heavy rainfall events in Tokyo. Ishihara (2013) analyzed the 3D radar reflectivity data of local severe storms on August 5, 2008, (known as Zoshigaya heavy rainfall) and showed their characteristics such as spatial extent, lifetime, and vertically integrated liquid water. Recent studies increasingly utilize polarimetric radar data, which demonstrate the inner structures of various cloud systems, in the Kanto region. For example, Yamauchi et al. (2013) revealed the vertical structure and its temporal variation of a tornadic supercell observed at Tsukuba on May 6, 2012. Sakurai et al. (2015) investigated the relationships between cloud-to-ground lightning activity and updraft characteristics in thunderstorms. However, the formation and development processes of convective systems in the Tokyo area are still unclear mainly because of the lack of observations.

In this context, the intensive observations of the Tokyo Metropolitan Area Convection Study for Extreme Weather Resilient Cities (TOMACS) have been conducted in the summer seasons of 2011-2013 (Nakatani et al. 2015). The activities and structures of convective systems in Tokyo and surrounding areas were captured by a variety of observations (Shoji 2018).

We used TOMACS data in this study to investigate mesoscale environmental conditions in two contrasting thunderstorms in the Tokyo metropolitan area during the TOMACS intensive observation period (IOP): the first thunderstorm was an extremely severe storm on August 26, 2011, and the second thunderstorm was a moderate thunderstorm on July 18, 2013. The formation processes of convective systems were examined using conventional observations, radiosonde soundings, and numerical simulations.

Another focus of our study was the impact of urbanization on precipitation. Fujibe et al. (2009) suggested the possibility of urban-induced positive precipitation anomaly on the basis of long term observation data in the Tokyo metropolitan area. However, it is difficult to establish the manner in which urbanization can modify the precipitation by using observation alone. Numerical modeling is considered a useful approach for investigating the processes of urban-related precipitation change. In a case study of the Zoshigaya heavy rainfall event, Souma et al. (2013) showed that both anthropogenic heat and artificial land cover increased the amount of precipitation and that the effect of artificial land cover was larger than that of anthropogenic heat in the numerical simulation. Kusaka et al. (2014) showed in simulations that urbanization increased the summertime precipitation amount in the Tokyo metropolitan area and reduced it in inland areas. 
Seino et al. (2018) suggested that a temperature rise of approximately $1{ }^{\circ} \mathrm{C}$ in central Tokyo has caused a $10 \%$ increase in August mean precipitation amount in eight-year August simulations. They also performed a composite analysis of 68 cases of afternoon rainfall without preceding precipitation to show that thermally induced change in circulation played a key role in enhancing urban rainfall. However, Shepherd (2013) indicated that there is still uncertainty and scientific debate about whether urban environments increase rainfall, decrease rainfall, or have no effect on rainfall. A certain proportion of simulations for individual rainfall events have shown negative or negligible changes in precipitation due to urbanization in the Tokyo area (Matheson and Ashie 2008; Shimoju et al. 2010; Inamura et al. 2011; Seino et al. 2018). Moreover, our knowledge of urban effects on rainfall, especially on heavy rainfall, and the possible mechanisms of these effects is still limited. To discuss the point, we performed comparative simulations to examine how precipitation modification can occur between current highly urbanized and less-urbanized conditions. In the next section, an outline of the radiosonde observation in TOMACS is introduced, and the modeling method is described. Section 3 presents the results of observations and simulations for the two heavy rain cases. Section 4 shows the similarities and differences between the two cases and presents discussions on the urban-related processes revealed in the comparative simulations. Section 5 concludes.

\section{Data and methods}

\subsection{Radiosonde observations}

TOMACS radiosonde observation aims to capture atmospheric environment in the heavy rainfall and understand the role of urban atmospheric boundary layer (ABL) processes in the development of a convective system. The observations took place for 34 days totally in summer and autumn of 2011-2013 as part of the TOMACS field campaign. The radiosondes were released at seven observation sites in the southern part of the Kanto Plain (Fig. 1, Table 1), mostly every three hours between 08:30 Japan Standard Time (JST, 00:00 UTC = 09:00 JST) and 20:30 JST. Radiosonde trajectory simulations using Monte Carlo technique were performed to predict the radiosonde falling area and avoid its landing in a densely populated area (Seino et al. 2014).

During the summertime TOMACS field campaign, radiosonde sounding data in four local heavy rain events were obtained. Among them, we focused on the August 26, 2011, case (Case 1), which is one of the

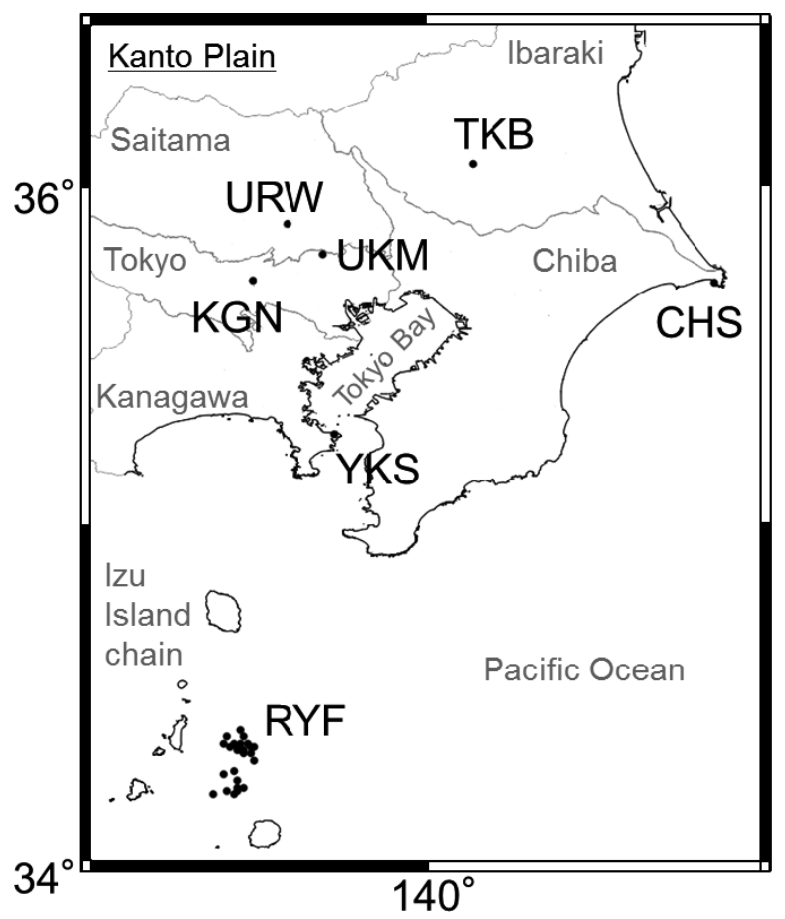

Fig. 1. Locations of the radiosonde observation sites. The location name and site information are listed in Table 1. This map is based on the "National Land Numerical Information (Coastal lines data)" published by the Ministry of Land, Infrastructure, Transport and Tourism of Japan.

severest storm events during the TOMACS IOP and caused flooding and traffic disruption in wide areas (Tokyo Regional Headquarters, Japan Meteorological Agency (JMA) 2011). The JMA recorded more than $100 \mathrm{~mm}$ of rainfall in the Tokyo area (in the radar/rain gauge analysis data product), and the development of two misocyclones and wind gusts in the western Tokyo were detected using data from the TOMACS dense ground observation network and the Doppler radar in Case 1 (Saito et al. 2013). Saito et al. (2018) numerically investigated the convective initiation and impact of modified model physics with the ensemble forecasts of this case. Another case on July 18, 2013, (Case 2) was examined for the sake of comparison. In Case 2, moderate storms were observed in limited areas at around Tokyo, and the maximum precipitation amount in the radar-rain gauge analyses was approximately $50 \mathrm{~mm}$. Radiosonde sounding data at Tsukuba and Yokosuka in Case 1, as well as those at Tsukuba, Urawa, Yokosuka, and Ryofu Maru in Case 2, were utilized in this study. 
Table 1. List of radiosonde observations. Site locations are shown in Fig. 1 by using abbreviations. The ward/city of the site is implemented when the site name differs from the city name.

\begin{tabular}{|c|c|c|c|c|c|}
\hline Sonde release site & & North Latitude & East Longitude & $\begin{array}{c}\text { Sonde release height } \\
\text { (AMSL) }\end{array}$ & $\begin{array}{l}\text { Observation year } \\
\text { (month) }\end{array}$ \\
\hline Tsukuba & TKB & $36^{\circ} 03^{\prime} 00^{\prime \prime}$ & $140^{\circ} 08^{\prime} 00^{\prime \prime}$ & $26 \mathrm{~m}$ & $\begin{array}{l}2011 \text { (Aug.-Oct.) } \\
2012 \text { (Aug.) } \\
2013 \text { (Jul.-Sep.) }\end{array}$ \\
\hline Urawa (Sakura Ward, Saitama) & URW & $\begin{array}{l}35^{\circ} 52^{\prime} 37^{\prime \prime} \\
35^{\circ} 52^{\prime} 27^{\prime \prime}\end{array}$ & $\begin{array}{l}139^{\circ} 35^{\prime} 12^{\prime \prime} \\
139^{\circ} 35^{\prime} 29^{\prime \prime}\end{array}$ & $\begin{array}{l}4 \mathrm{~m} \\
7 \mathrm{~m}\end{array}$ & $\begin{array}{l}2013 \text { (Jul.) } \\
2013 \text { (Sep.) }\end{array}$ \\
\hline Ukima (Kita Ward, Tokyo) & UKM & $35^{\circ} 47^{\prime} 19^{\prime \prime}$ & $139^{\circ} 41^{\prime} 31^{\prime \prime}$ & $22 \mathrm{~m}$ & $\begin{array}{l}2011 \text { (Sep.-Oct.) } \\
2013 \text { (Sep.) }\end{array}$ \\
\hline Koganei & KGN & $35^{\circ} 42^{\prime} 32^{\prime \prime}$ & $139^{\circ} 29^{\prime} 16^{\prime \prime}$ & $76 \mathrm{~m}$ & 2011 (Oct.) \\
\hline Choshi & CHS & $35^{\circ} 42^{\prime} 19^{\prime \prime}$ & $140^{\circ} 50^{\prime} 29^{\prime \prime}$ & $4 \mathrm{~m}$ & 2012 (Aug.) \\
\hline Yokosuka & YKS & $35^{\circ} 15^{\prime} 31^{\prime \prime}$ & $139^{\circ} 43^{\prime} 30^{\prime \prime}$ & $98 \mathrm{~m}$ & $\begin{array}{l}2011 \text { (Aug.-Oct.) } \\
2012 \text { (Aug.) } \\
2013 \text { (Jul.) }\end{array}$ \\
\hline Ryofu Maru (the Pacific Ocean) & RYF & $34^{\circ} 20^{\prime}-39^{\prime}$ & $139^{\circ} 37^{\prime}-49^{\prime}$ & $5 \mathrm{~m}$ & 2013 (Jul.) \\
\hline
\end{tabular}

Sugawara et al. (2015) argued the ABL height variations at the sites of Tsukuba (rural), Ukima (urban), Koganei (suburban), and Yokosuka (coastal) on the basis of the radiosonde observation data on sunny days in September and October. They concluded that they were attributed to differences in surface sensible heat flux between urban and rural sites. The urban boundary layer structure and convective cloud formation are further discussed in Sugawara et al. (2018).

\subsection{Numerical model}

We performed numerical simulations for Cases 1 and 2 by using the JMA nonhydrostatic model (NHM) (Saito et al. 2006) to investigate how the mesoscale environment evolved during storm formation. The horizontal grid interval was $2 \mathrm{~km}$, and the model domain covered central Japan, including the mountainous areas surrounding the Kanto Plain (Fig. 2). The specifications of NHM in this study are summarized in Table 2. We employed the square prism urban canopy (SPUC) scheme (Aoyagi and Seino 2011) in the highly urbanized grid cells where the area fraction of artificial land use in a unit cell (building lots, roads, and other artificial land covers such as airports) occupied more than $80 \%$. The area fractions of land use categories in each grid cell were determined from the $100 \mathrm{~m}$-mesh Digital National Land Information Dataset. The surface heat and radiation exchange processes affected by the canopy elements, such as buildings, are described in the SPUC scheme. The spatial distribution of time-varying anthropogenic heat in the metropolitan area (Senoo et al. 2004) is also

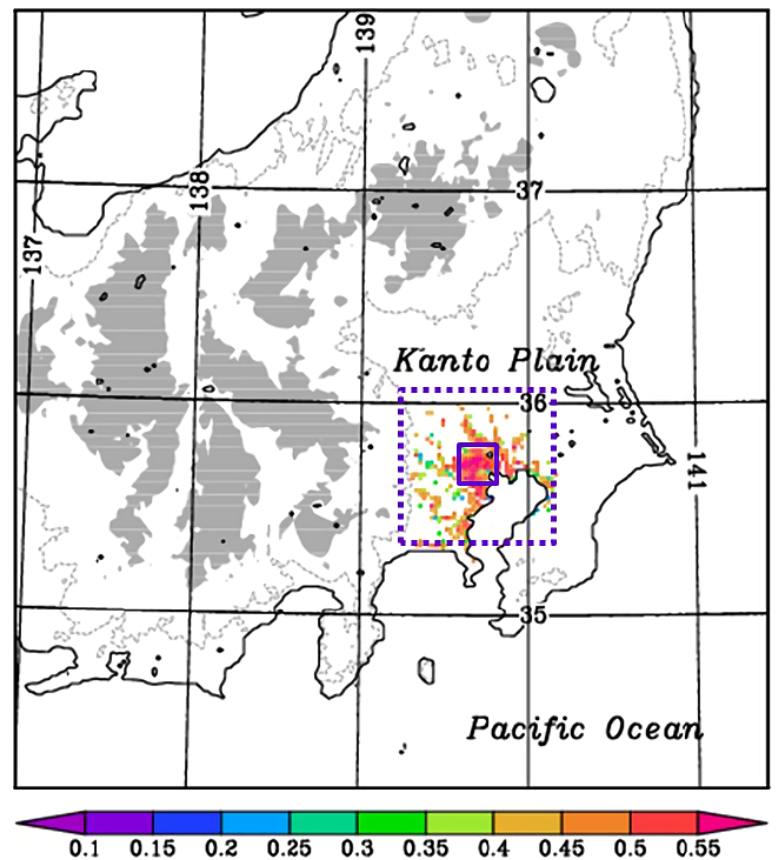

Fig. 2. Model domain and topography. The colors denote the building fraction of grid cells to which SPUC was applied. The dotted gray lines are the $200 \mathrm{~m}$ topographic contour, and the gray shading indicates regions higher than $1000 \mathrm{~m}$ above sea level. A purple rectangle (dotted line) outlines the reference urban area, which covers most of the SPUC-applied model grid cells, and the inner rectangle represents the central urban area roughly covering the 23 wards of Tokyo, which are the most built-up areas, for the discussion in Sections 3 and 4. 
Table 2. Specifications of NHM used in this study.

\begin{tabular}{ll}
\hline \multicolumn{1}{c}{ Governing equations } & \multicolumn{1}{c}{ Fully compressible, non-hydrostatic } \\
\hline Discretization & Grid point method, $\mathrm{z}^{*}$-coordinate \\
Treatment of advection & 4th order flux form, advection corrected \\
Map projection & Lambert conformal projection \\
Topography & GTOPO30 \\
Cloud microphysics & Bulk scheme with ice phase predicting $\mathrm{q}_{\mathrm{v}}, \mathrm{q}_{\mathrm{c}}, \mathrm{q}_{\mathrm{r}}, \mathrm{q}_{\mathrm{i}}, \mathrm{q}_{\mathrm{s}}, \mathrm{q}_{\mathrm{g}}$ \\
Cumulus parameterization & Not used \\
Turbulent closure & Improved Mellor-Yamada level3 (Nakanishi and Niino 2006) \\
Cloud radiation & Kitagawa (2000) \\
Clear sky radiation & Yabu et al. (2005) \\
Clouds in radiation processes & Partial condensation scheme \\
Surface flux & Beljaars and Holtslag (1991) \\
Urban canopy & SPUC scheme (Aoyagi and Seino 2011) \\
Initial and boundary conditions & Mesoscale analyses of JMA \\
Initial time (Integration period) & 2011.8.26 03 JST (21 h) \\
& 2013.7.18 09 JST (15 h) \\
\hline
\end{tabular}

considered in SPUC.

A pair of comparative simulations was performed to examine the urban impact on precipitation. In one of the simulations, realistic current urban surface conditions were used (CRNT experiment). In the other simulation, less-urbanized surface conditions were assumed (LURB experiment). In the LURB experiment, the urbanized surface was treated as a flat surface with the thermal properties of a concrete slab without considering the influences of the urban canopy on the surface energy balance. As shown later, the LURB experiment simulated generally lower urban surface air temperature than the CRNT experiment because of less heat storage within the surface materials and the omitted anthropogenic heat; thus, a reduced urban heat island was represented. The parameter settings in these experiments were the same as those described in detail by Seino et al. (2018).

\section{Results}

\subsection{Case 1: August 26, 2011}

a. Synoptic-scale and mesoscale overview for Case 1

On August 26, 2011, a severe thunderstorm developed over the Tokyo metropolitan area. Heavy rainfall exceeding $100 \mathrm{~mm}$ was observed in Tokyo and neighboring prefectures in the afternoon hours from 12 to 24 JST (Fig. 3). From a synoptic-scale point of view, the heavy rainfall occurred under the influence of a stationary front approaching from the northern part of the mainland of Japan (Fig. 4). At 09 JST, the stationary front and associated rainy area were located to the north of the Kanto region. By 21 JST, the stationary front moved down to the southern coast of the Kanto region.

Figure 4 also shows that two typhoons existed at around $20^{\circ} \mathrm{N}$. Generally, tropical cyclones in the far south of Japan can lead to warm and moist conditions in the lower atmosphere and affect the activities of convective cloud formation (Tsuguti and Kato 2014). In the present case, relatively high temperature and humidity in the lower levels can be seen at around the southern coast of western Japan and offshore the Kanto area, which provided the basic environment for this heavy rainfall event. However, warm and humid conditions around that area had presented for several days, and the warm southerly inflow south of the Kanto area was not extremely active on August 26, 2011.

Figure 5 demonstrates the spatiotemporal variations in radar rainfall intensity and surface wind over the Kanto region in the afternoon. By $12 \mathrm{JST}$, the rainfall area gradually extended to the northern part of the Kanto region, whereas the southern Kanto region had a smaller cloud amount and 50-100\% sunshine rates. By $13 \mathrm{JST}$, surface air temperature had risen to $31^{\circ} \mathrm{C}$ along the southern coastal areas. Southerly winds prevailed on the southern coast around Tokyo Bay, and easterly winds prevailed over the eastern Kanto Plain. By 14 JST, the E-S wind pattern (Fujibe et al. 2002) formed, and convective systems developed between the southerly and easterly flows in coastal areas, ahead of the broad frontal precipitation covering the northern Kanto region (Fig. 5c). In the mature stage of the storm at around 16-17 JST, torrential rain (more than $80 \mathrm{~mm}$ per hour) was recorded at stations SagamiharaChuo (94 $\left.\mathrm{mm} \mathrm{h}^{-1}\right)$, Nerima $\left(90.5 \mathrm{~mm} \mathrm{~h}^{-1}\right)$, and Haneda 


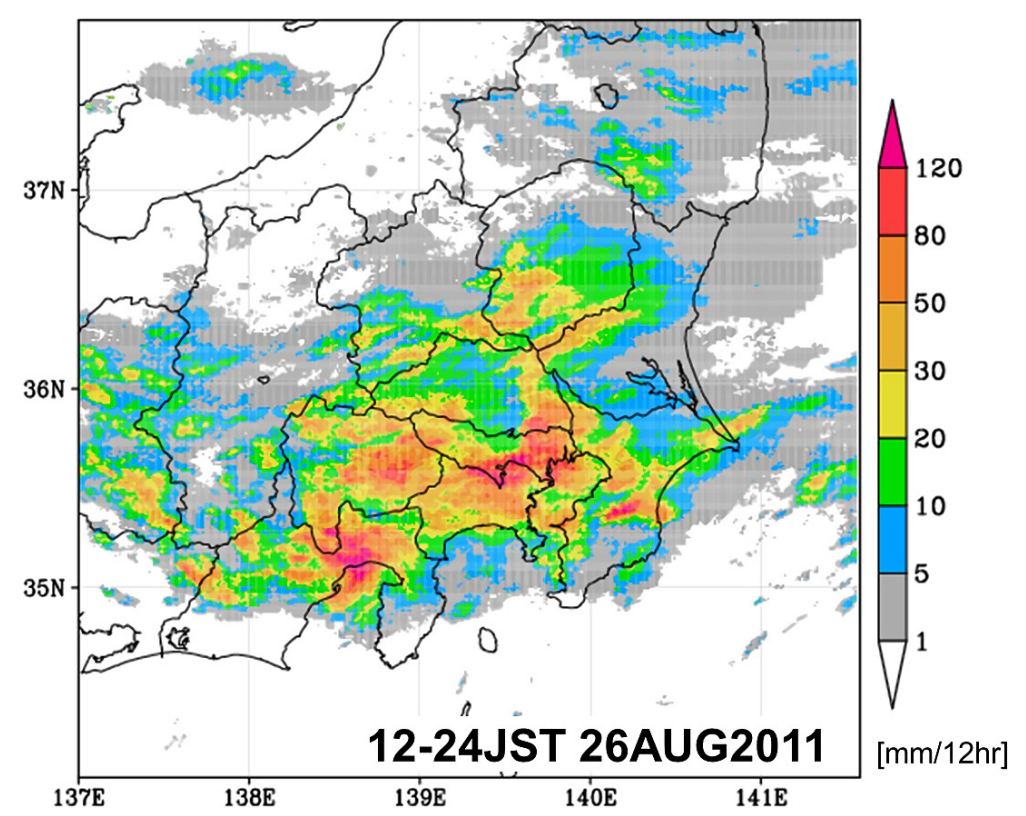

Fig. 3. Radar-rain gauge analyzed precipitation amount in the afternoon (12-24 JST) of August 26, 2011.

(a) 09 JST 26AUG2011

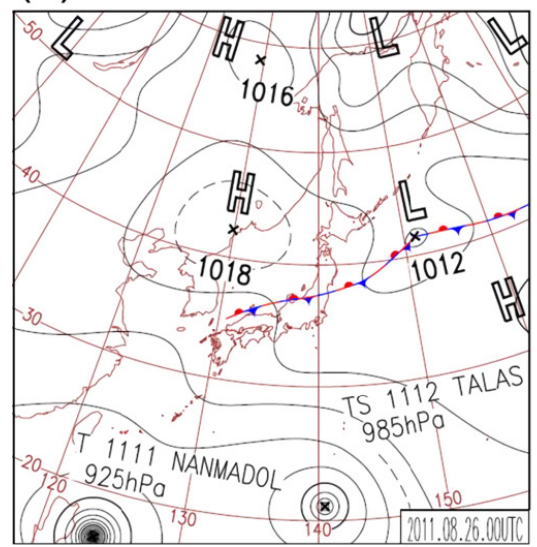

(b) 21 JST 26AUG2011

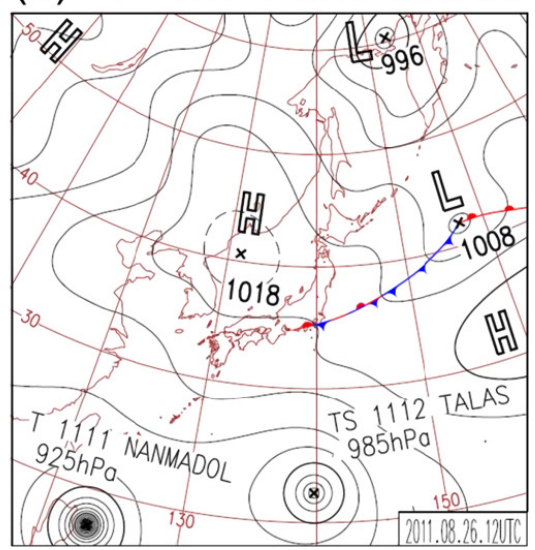

Fig. 4. Weather chart of (a) 09 and (b) 21 JST August 26, 2011.

$\left(82 \mathrm{~mm} \mathrm{~h}^{-1}\right)$ of the Automated Meteorological Data Acquisition System (AMeDAS). In later hours, convective systems moved gradually southward, merged with the frontal precipitation system, and weakened.

\section{b. Results of observation analysis for Case 1}

Intensive radiosonde observations were made at Yokosuka and Tsukuba in this case (Fig. 6, see Fig. 1 for site locations). At Tsukuba to the northeast of Tokyo, westerly winds were observed at lower atmo- spheric levels at the 08:30 JST operational sounding. AMeDAS data at Tsukuba show that surface wind direction changed to easterly at around 11 JST (see Fig. $9 \mathrm{~b})$. The easterly winds were observed in the lowest 1000-1500 $\mathrm{m}$ atmospheric layer in soundings at 11:30 and 14:30 JST. The convective available potential energy (CAPE), estimated from temperature and moisture profiles increased from $1304 \mathrm{~J} \mathrm{~kg}^{-1}$ at $08: 30 \mathrm{JST}$ to $2094 \mathrm{~J} \mathrm{~kg}^{-1}$ at 11:30 JST. At 14:30 JST, the CAPE decreased to $819 \mathrm{~J} \mathrm{~kg}^{-1}$ because of the slight decrease 

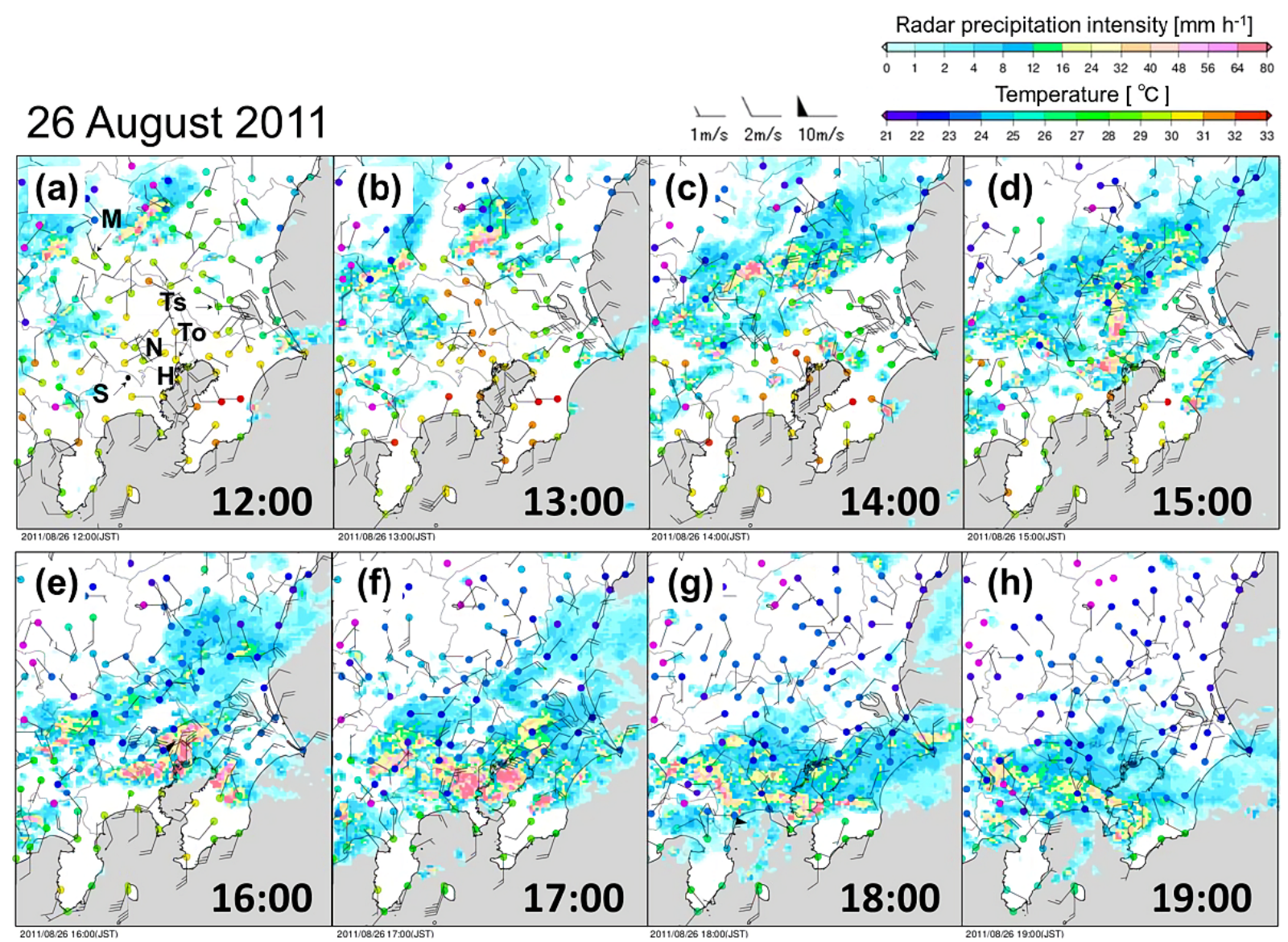

Fig. 5. Precipitation intensity (for the previous $5 \mathrm{~min}$ ) observed from the JMA radar network; surface winds and temperatures at stations of AMeDAS in the afternoon of August 26, 2011. Symbols S, N, H in Fig. 5a denote stations Sagamihara-Chuo, Nerima, and Haneda, respectively, where heavy rainfall was observed at approximately 16 JST. Symbols M, Ts, and To in Fig. 5a respectively denote Maebashi, Tsukuba, and Tokyo stations for the time series in Figs. 9 and 24.

in near-surface temperature and specific humidity, and the easterly wind became stronger with a maximum speed of approximately $9 \mathrm{~m} \mathrm{~s}^{-1}$ at the $500 \mathrm{~m}$ level. At Yokosuka to the south of Tokyo, southerly wind with a maximum wind speed of $7 \mathrm{~m} \mathrm{~s}^{-1}$ prevailed in the lowermost $1000 \mathrm{~m}$ layer in every sounding (10:34, 14:27, and 17:12 JST) on the day (Figs. 6d-f). Although the near-surface equivalent potential temperature (EPT) in the morning was almost the same as at Tsukuba (350 $\mathrm{K})$, the CAPE at Yokosuka was less than $1000 \mathrm{~J} \mathrm{~kg}^{-1}$ at 10:34 JST and fell to $571 \mathrm{~J} \mathrm{~kg}^{-1}$ in the $14: 27 \mathrm{JST}$ sounding. In the 17:12 JST sounding, the near-surface EPT increased to $355 \mathrm{~K}$, and the CAPE increased to $1777 \mathrm{~J} \mathrm{~kg}^{-1}$. These sounding results demonstrate the time-varying thermal contrast between the two inflows over the Kanto region during the afternoon of August
26.

Surface wind observations show that the easterly flow from the eastern coastal areas spread into the inland part in the morning hours (figure not shown). The visible rapid scan images of the geostationary meteorological satellite (MTSAT-1R) depict the formation of arc-shaped cloud lines at the leading edge of the easterly flow at approximately 12 JST (Fig. 7). In later hours, convective clouds developed around Tokyo along the boundary of the easterly and southerly winds, as shown in Fig. 5.

\section{c. Results of modeling analysis for Case 1}

In the model results for the afternoon (12-24 JST) of August 26, 2011, (Fig. 8a), the areas of heaviest rainfall $(>100 \mathrm{~mm})$ reasonably matched the coastal 
(a)

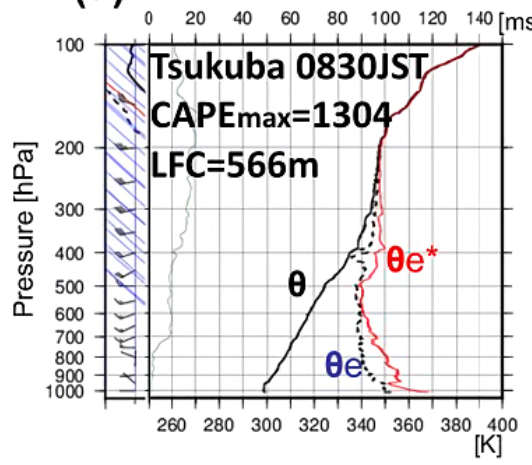

(d)

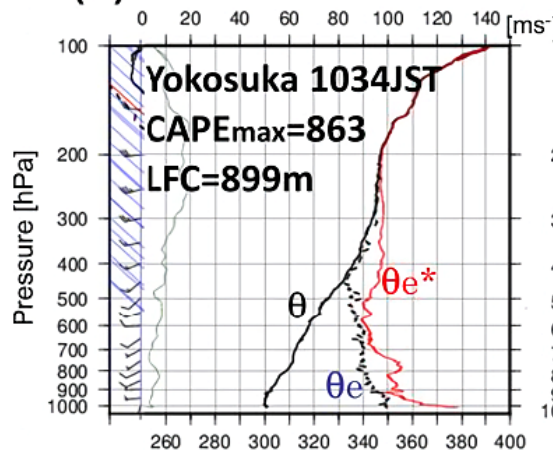

$[\mathrm{K}]$ (b)

26 August 2011

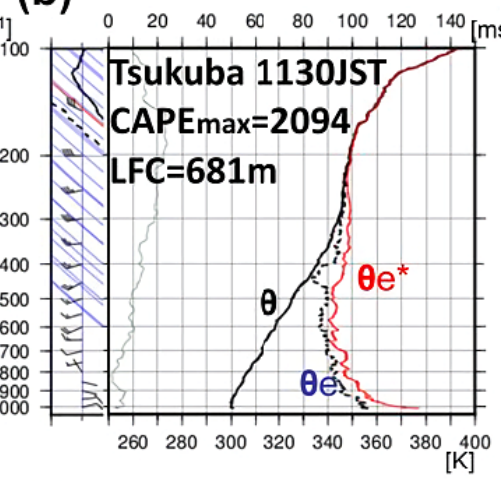

(e) (c)

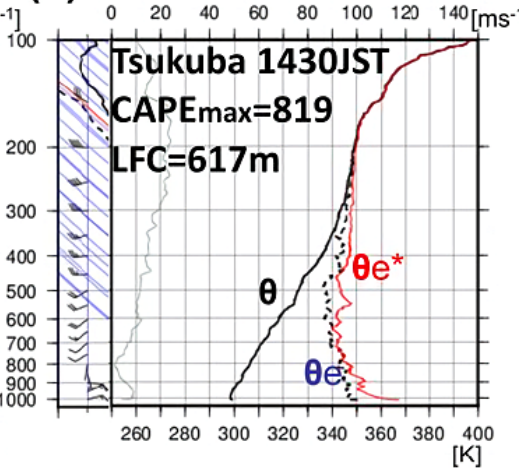

(f)
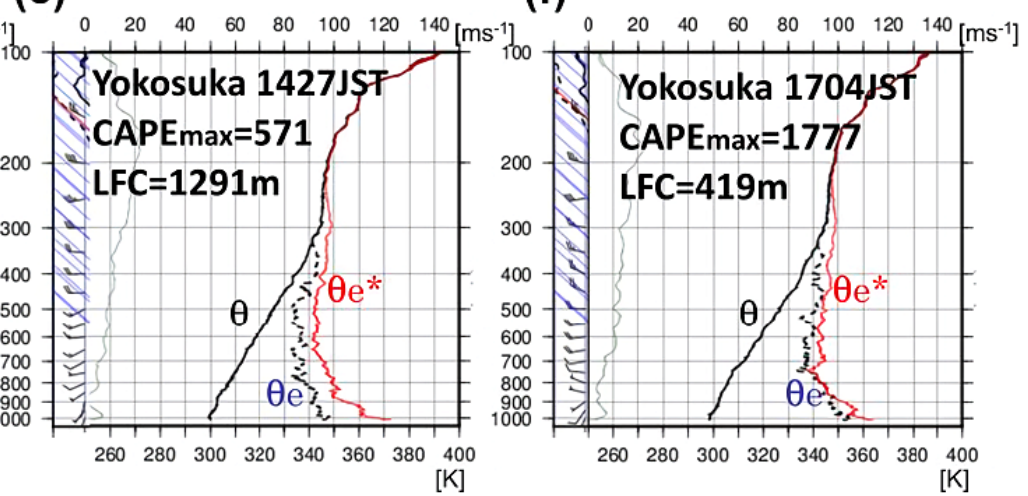

Fig. 6. Observed vertical profiles of potential temperature $(\theta)$, EPT $(\theta e)$, and EPTS $\left(\theta e^{*}\right)$ at Tsukuba (top) and Yokosuka (bottom).

(a) 12 JST 26AUG2011

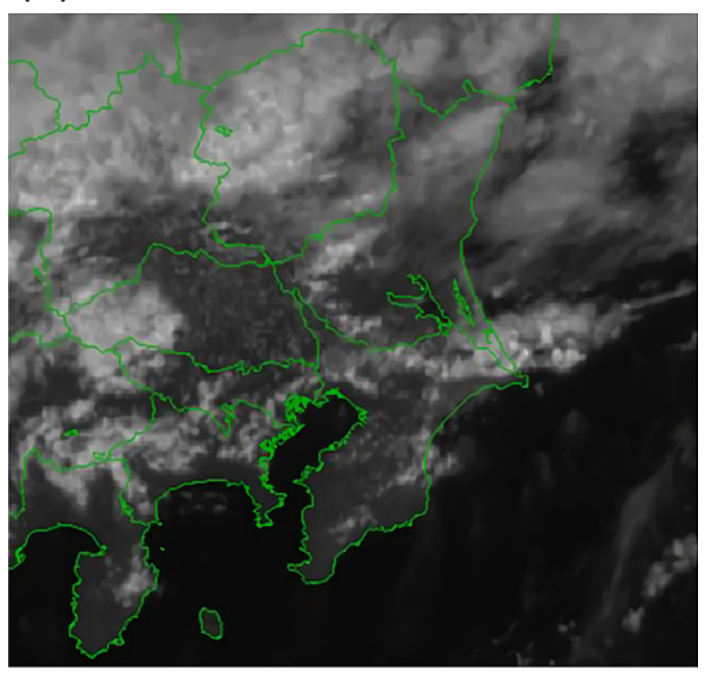

(b) 14 JST 26AUG2011

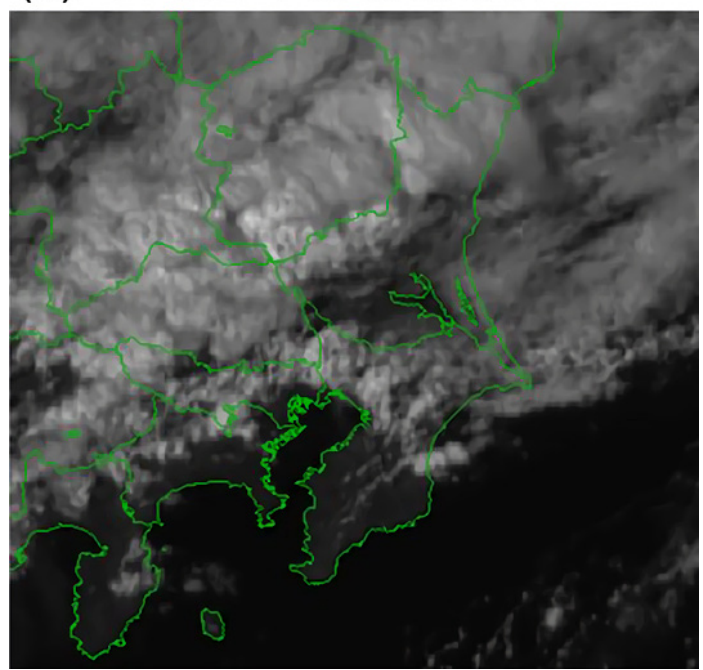

Fig. 7. MTSAT-1R visible rapid scan images over the Kanto region at (a) 12 and (b) 14 JST on August 26, 2011. 
(a) CRNT

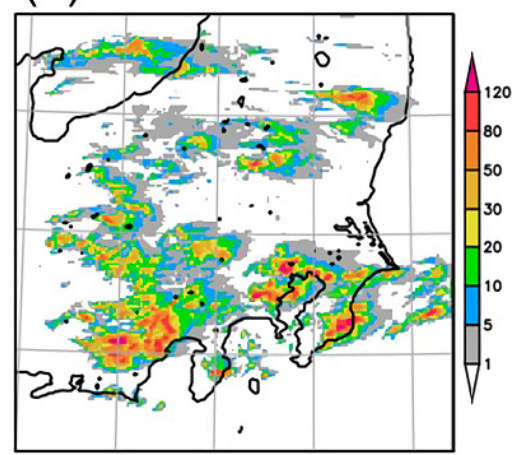

$[\mathrm{mm} / 12 \mathrm{hr}]$ (b) LURB

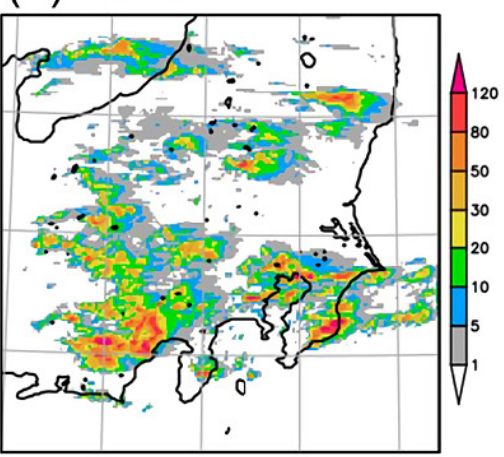

$[\mathrm{mm} / 12 \mathrm{hr}]$ (c) CRNT-LURB

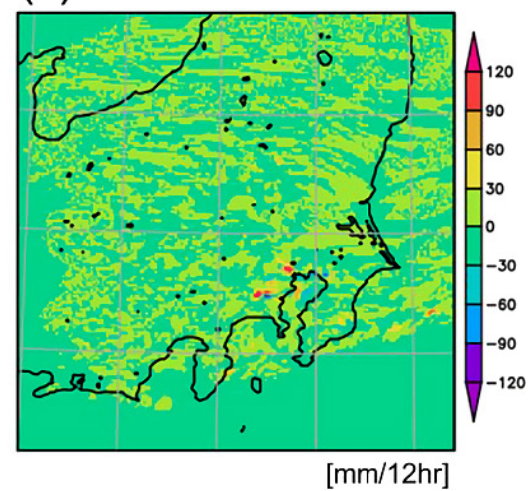

Fig. 8. Simulated precipitation amount in the afternoon (12-24 JST) of August 26, 2011, in (a) the CRNT experiment, (b) the LURB experiment, and (c) the difference between the experiments (CRNT-LURB).

(a) Maebashi 20110826

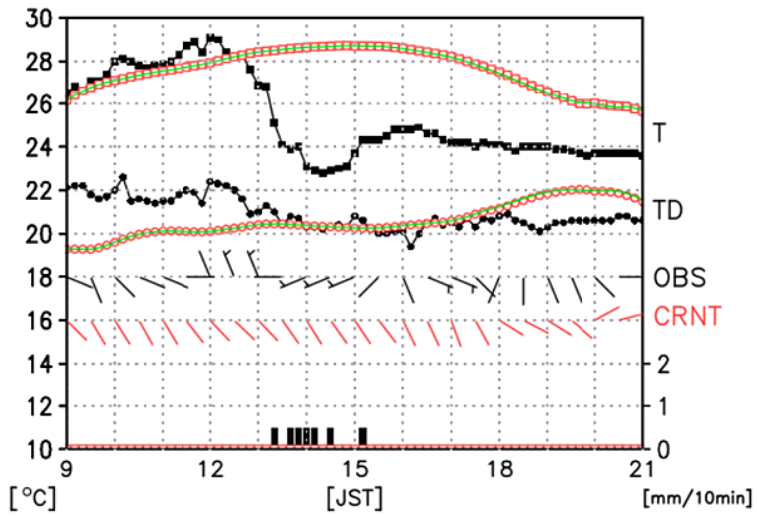

(c) Tokyo 20110826

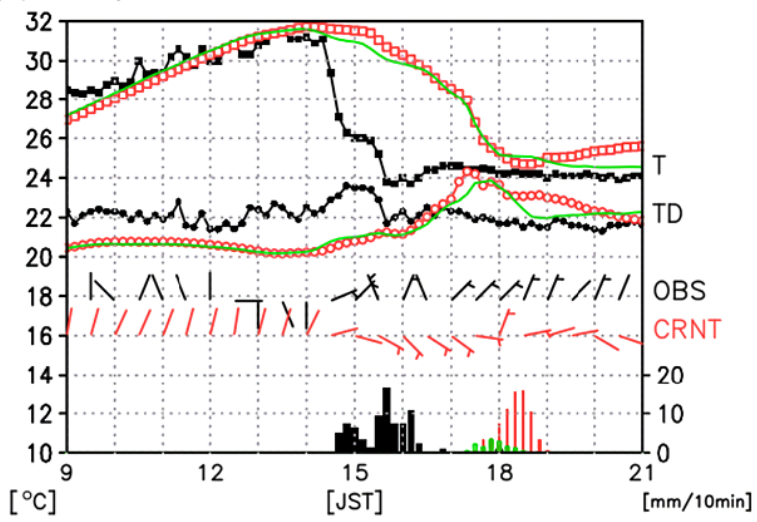

areas where the most intense rainfall was observed (see Fig. 3); however, the model underestimated precipitation in the inland part of the Kanto Plain. The simulated and observed time series of surface data at some stations (Maebashi in the inland area, Tsukuba,

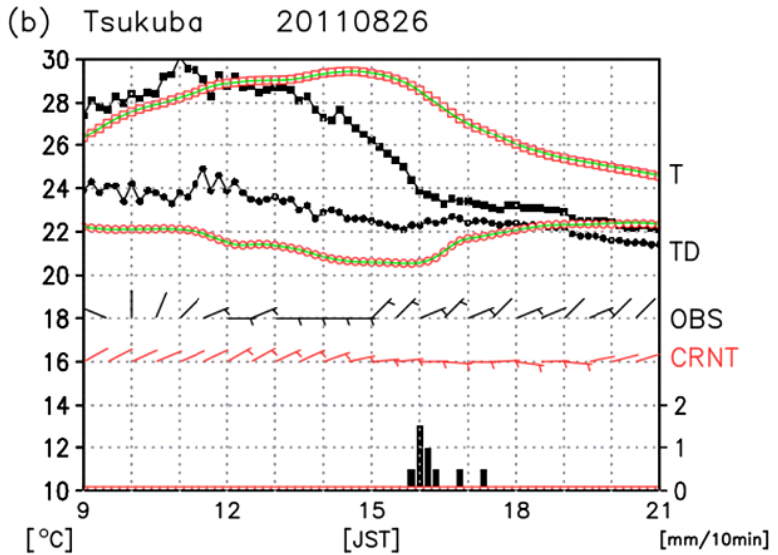

Fig. 9. Time series of observed and simulated surface meteorological data at (a) Maebashi, (b) Tsukuba, and (c) Tokyo for 09-21 JST on August 26, 2011 (see Fig. 5a for station locations). Black color denotes observation, red color denotes the CRNT experiment, and green color denotes the LURB experiment. A long barb indicates $10 \mathrm{~m} \mathrm{~s}^{-1}$, a short barb indicates $5 \mathrm{~m} \mathrm{~s}^{-1}$, no barb indicates winds less than $3 \mathrm{~m} \mathrm{~s}^{-1}$.

and Tokyo) show that the simulated temperatures agreed fairly well with the observation before the rainfall, but the simulated dew point temperatures were approximately $2^{\circ} \mathrm{C}$ lower than those observed (Fig. 9). The underestimation of the early afternoon 
(a)

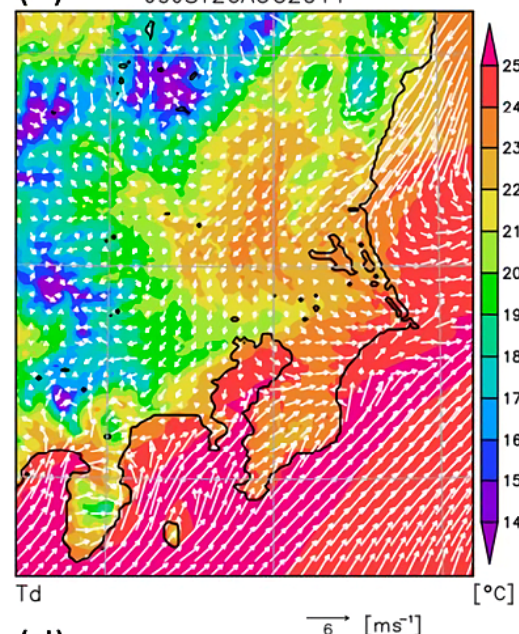

(d) 12-15JST26AUG2011

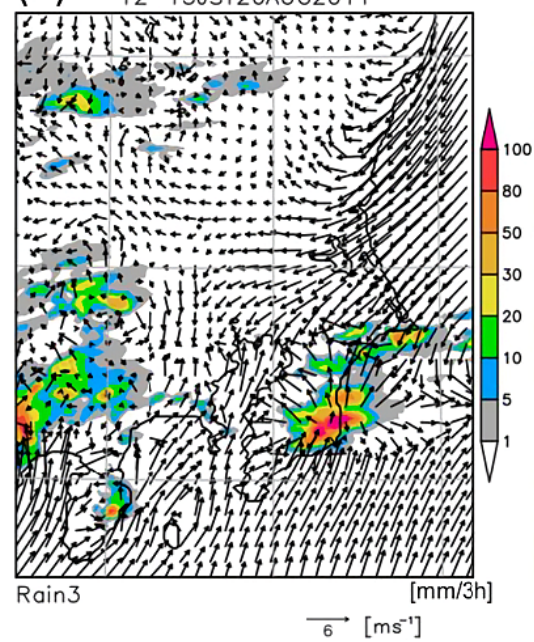

(b)

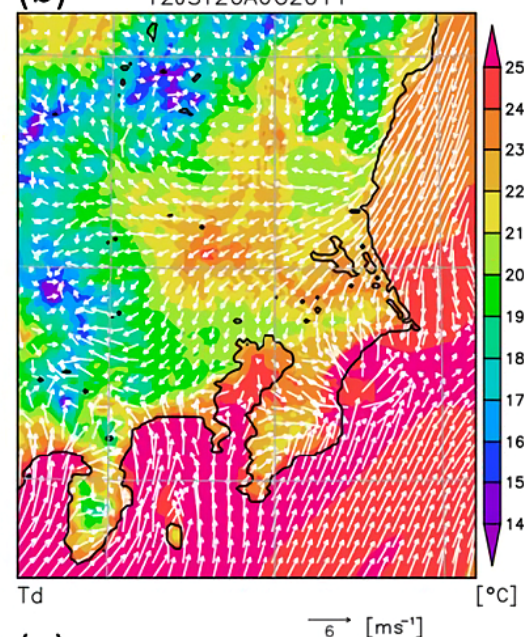

(e)

15JST26AUG2011

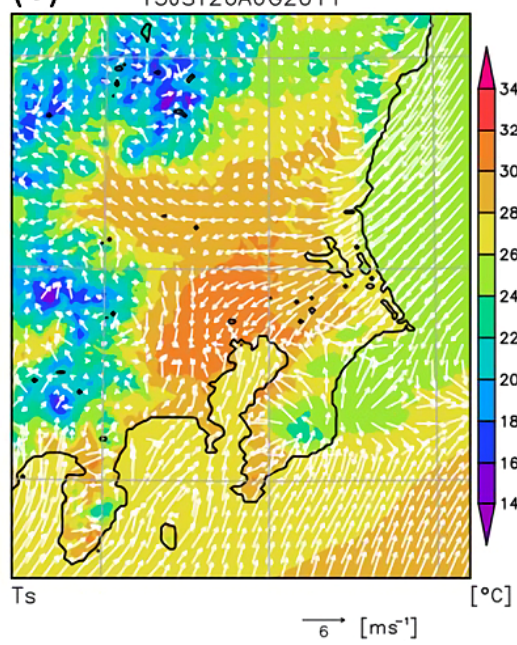

(c) 15JST26AUg2011
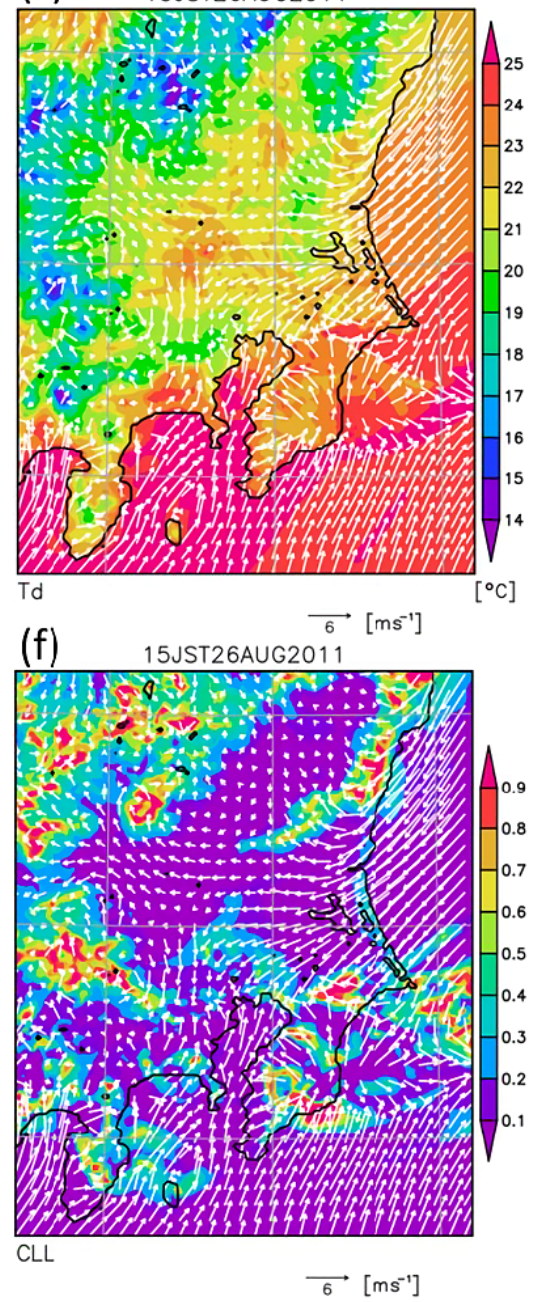

Fig. 10. Simulated dew point temperature distribution at (a) 09, (b) 12, and (c) 15 JST, and (d) simulated three hourly precipitation amount, (e) surface air temperature, and (f) low-level cloud amount diagnosed in the CRNT experiment at 15 JST on August 26, 2011.

rainfall, probably due to the underestimation of the near-surface water vapor amount, and the resultant absence of the cold outflow from the northern part of the Kanto Plain may account for the delayed onset of rainfall in the urban area (Fig. 10d). Nevertheless, the simulation reproduced the extension of easterly flow from the eastern coast and the relatively high dew point temperature at its leading edge (Figs. 10a-c), as well as the extension of southerly flow onshore from the southern coast. The formation of the E-S wind pattern appeared by 15 JST. The early afternoon temperature rise in the urban area was reasonably well simulated, although the delay in the onset of rainfall led to overestimated surface air temperatures at 15 JST (Fig. 10e). The simulated low-level cloud cover at 15 JST (Fig. 10f) resembled the observed cloud cover at 14 JST (Fig. 7b).

The onset of rainfall around central Tokyo was simulated at 16 JST (Fig. 11). The widest extent of rainfall in the urban area was simulated at approximately 18 JST, two hours later than shown in the observations. Simulated hourly precipitation, surface winds, and horizontal divergence field (Figs. 11, 12) show that a convergence line formed between the northeasterly and southerly airflows and stayed near central Tokyo roughly from 15 to 18 JST. Convective 
(a)

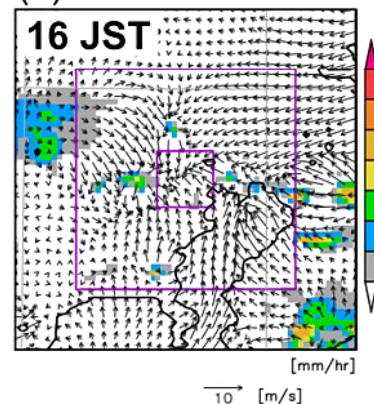

(e)

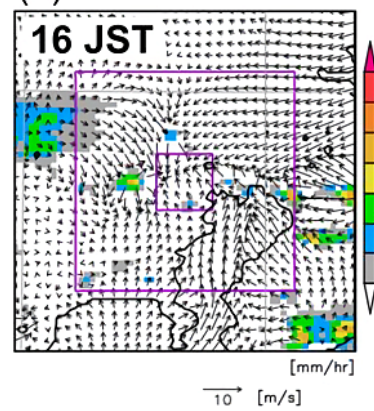

\section{CRNT}
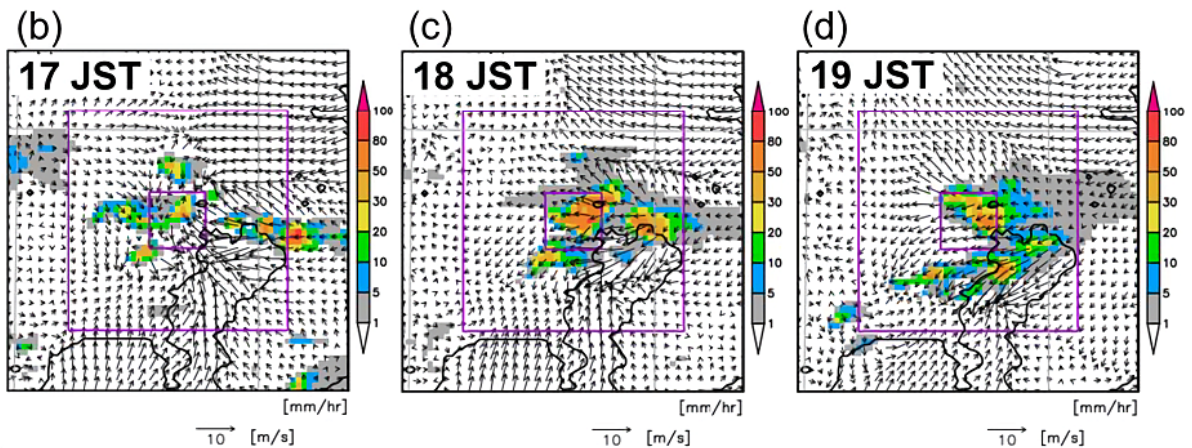

LURB

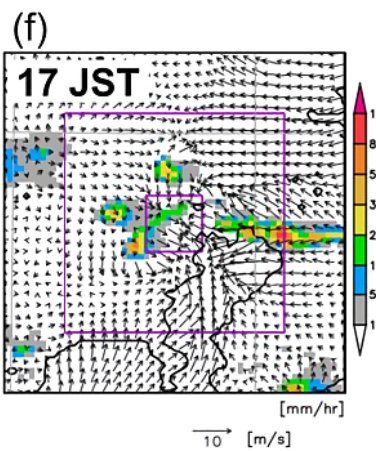

(g)

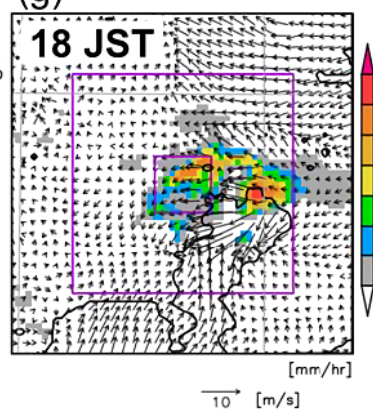

(h)

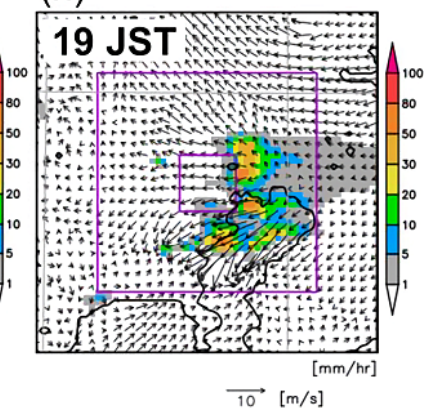

Fig. 11. Simulated hourly precipitation amount and surface winds of the CRNT experiment (top, a-d) and the LURB experiment (bottom, $\mathrm{e}-\mathrm{h}$ ) in the afternoon of August 26, 2011. Rectangles indicate the reference urban domain (outer one) and the central urban area (inner one).

(a)

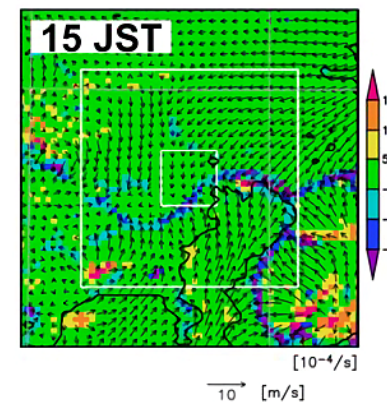

(b)

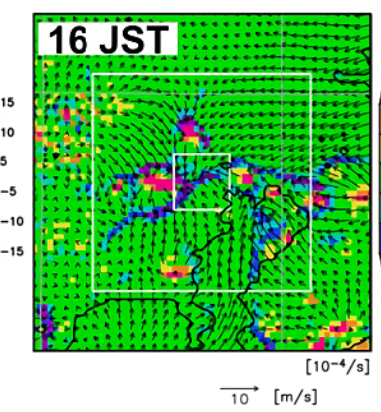

CRNT

(c)

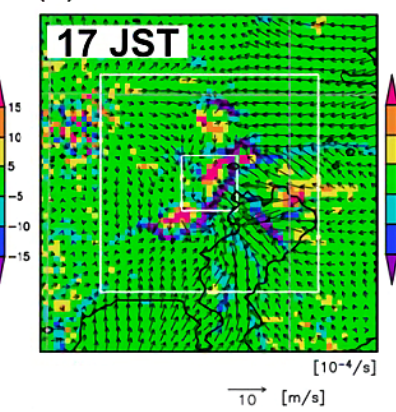

(d)

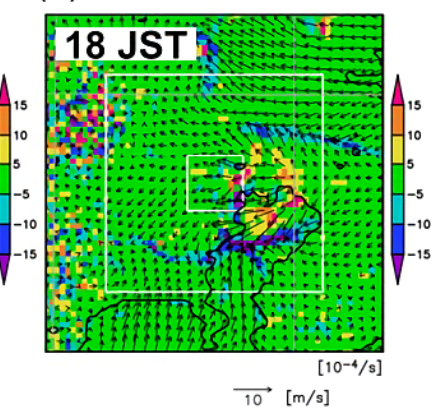

Fig. 12. Simulated divergence field of the CRNT experiment at the lowest model level in the afternoon of August 26, 2011. Rectangles indicate the reference urban domain (outer one) and the central urban area (inner one).

clouds were initiated along this line in the early evening. An additional convergence line formed between the southerly inflow over Tokyo Bay and an outflow from the previously developed convective system likely contributed to the development of convective systems around Tokyo.

The LURB experiment simulated a rainfall distribution generally resembling that from the CRNT exper- 
iment (Figs. 8a, b). This finding means that the severe thunderstorms on August 26 basically resulted from meteorological factors other than the urban effect. However, the amount of rainfall in the central urban area was smaller in the LURB experiment (Fig. 8c).

At 16 JST, the hourly rainfall distributions differed little between the CRNT and LURB experiments (Figs. $11 \mathrm{a}$, e). At 17 JST, the LURB experiment simulated less rainfall than the CRNT experiment in the central urban area (Figs. 11b, f). This difference between the two experiments increased at 18 and 19 JST. Figure 13 indicates that at $16 \mathrm{JST}$, one hour before the precipitation onset, the simulated surface air temperature in the warm urban area was approximately $1.5^{\circ} \mathrm{C}$ higher in the CRNT experiment than in the LURB experiment. The associated low pressure anomaly within the central urban area was also found in the CRNT experiment. These differences were greatest close to the convergence line. Relevant changes in circulation are shown in Fig. 14. In the CRNT experiment, surface convergence was intensified $\left(18 \times 10^{-4} \mathrm{~s}^{-1}\right.$ in CRNT and $13 \times 10^{-4} \mathrm{~s}^{-1}$ in LURB along line $\mathrm{AB}$ in the upper panels), and the stronger ascending motion $\left(1.9 \mathrm{~m} \mathrm{~s}^{-1}\right.$ in CRNT and $1.1 \mathrm{~m} \mathrm{~s}^{-1}$ in LURB at approximately $1500 \mathrm{~m}$ height) was found in the vertical cross section; these phenomena may have led to the efficient formation of convective clouds and the increase in precipitation in the urban area. It should be noted that the near-surface water vapor mixing ratio near the convergence zone did not increase in the CRNT experiment (Fig. 13d). (a)

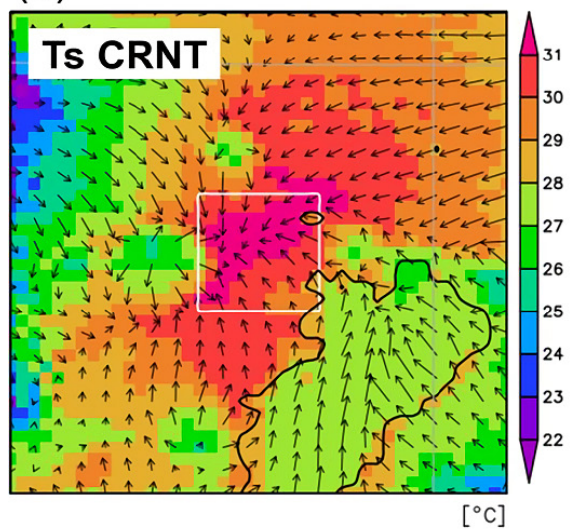

(c)

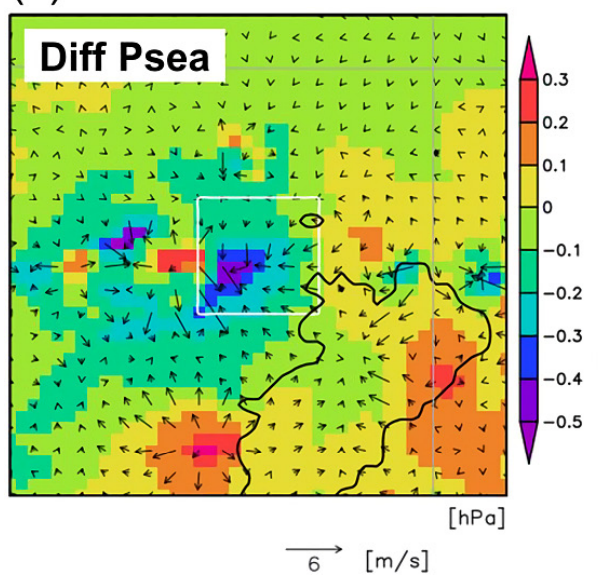

(b)

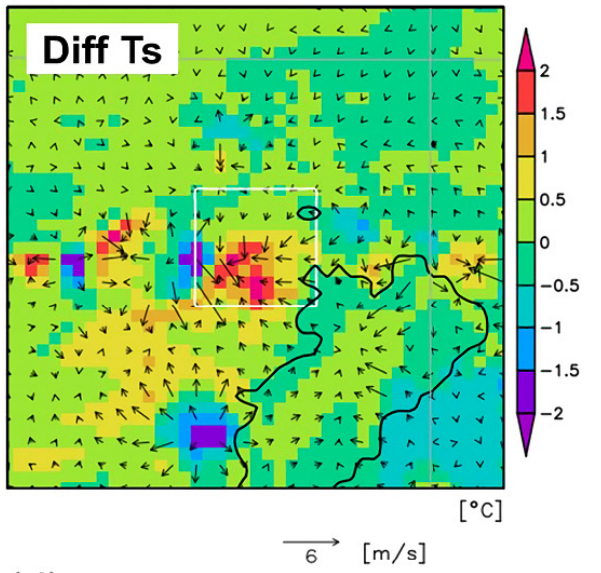

(d)

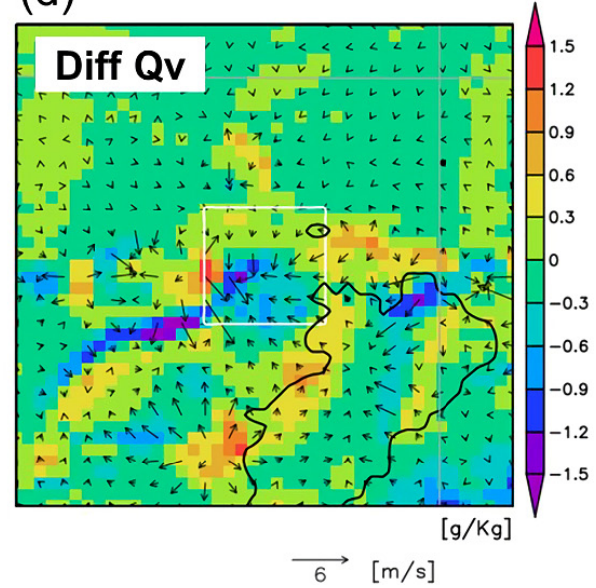

Fig. 13. Simulation results at 16 JST on August 26, 2011, for the (a) surface air temperature $\left(\mathrm{T}_{\mathrm{s}}\right)$ of the CRNT experiment and differences (CRNT-LURB) in (b) surface air temperature, (c) sea-level pressure $\left(\mathrm{P}_{\text {sea }}\right)$, and $(\mathrm{d})$ water vapor mixing ratio $\left(Q_{v}\right)$ at the lowest model level between the CRNT and LURB experiments. 


\subsection{Case 2: July 18, 2013}

a. Synoptic-scale and mesoscale overview for Case 2 We examined the convective systems that developed in Tokyo and Saitama Prefecture in the evening of July 18, 2013. As shown in Fig. 15, a low pressure system formed in the northern part of the mainland of Japan at 09 JST and moved to the east of Japan at $21 \mathrm{JST}$. The rainfall due to this synoptic disturbance was observed in parts of northern and central Japan early that morning. In the Kanto region, rainfall along the southern coastal area ceased by 09 JST. Fair conditions in the afternoon led to temperatures of up to $33^{\circ} \mathrm{C}$ in the Kanto Plain.

Convective clouds began to develop at approximately 17 JST in the southwestern part of Saitama Prefecture and moved eastward to Tokyo (Fig. 16). Thereafter, convective systems forming in the eastern part of Saitama Prefecture moved southward and developed in Tokyo. These convective systems resulted in approximately $50 \mathrm{~mm}$ of rainfall from 12 to $24 \mathrm{JST}$ on July 18, 2013 (Fig. 17). The thunderstorms affected relatively limited areas, and the observed amount and spatial extent of rainfall were less than in Case 1.

\section{b. Results of observation analysis for Case 2}

In this case, radiosonde observations were performed at Yokosuka, Urawa, and Tsukuba and at JMA research vessel Ryofu Maru. The radiosonde soundings at Ryofu Maru were conducted near the Izu Island chain from July 18-22, 2013 (see Fig. 1). The shipboard soundings clearly show time variations in temperature and moisture at the sea off southern Kanto; the increase in temperature and vapor mixing ratio in the lower atmosphere was captured twice: on (a)

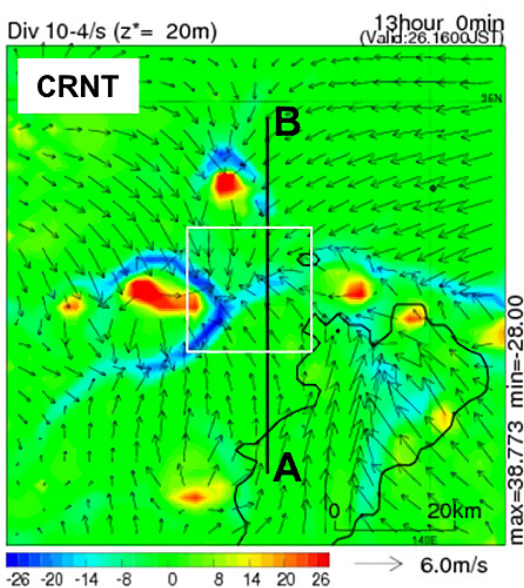

(c)

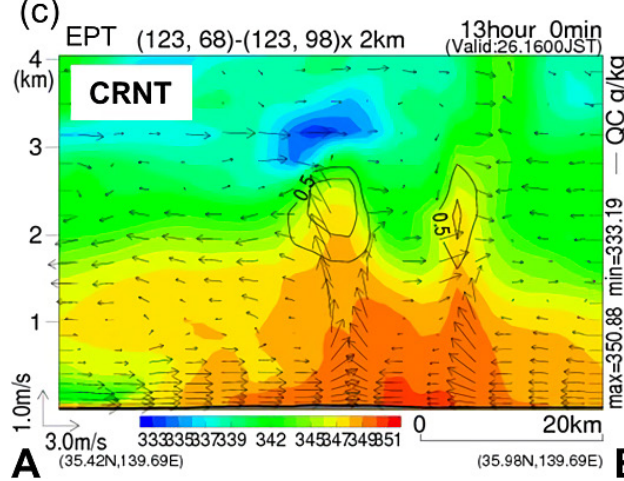

(b)

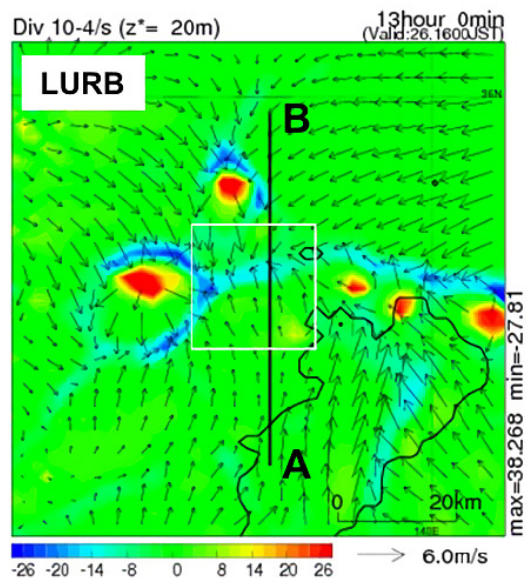

(d)

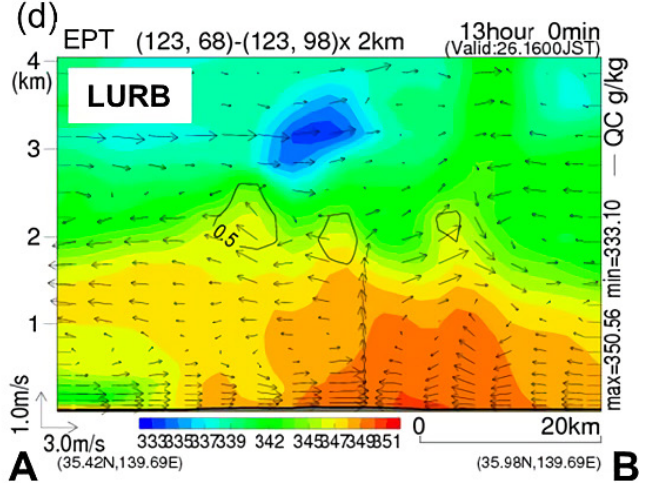

Fig. 14. Simulated horizontal divergence field at the lowest model level in the (a) CRNT experiment and (b) LURB experiment at 16 JST on August 26, 2011. The white rectangles indicate the central urban area. The vertical cross sections (along thick lines A-B in Figs. 14a, b) shows EPT and wind vectors for the (c) CRNT experiment and (d) LURB experiments at the same time. Contour lines in the vertical cross sections denote cloud water contents at $0.5 \mathrm{~g} \mathrm{Kg}^{-1}$ intervals. Wind barbs are drawn at intervals of two horizontal grids. 
(a) 09 JST 18JUL2013

(b) 21 JST 18JUL2013
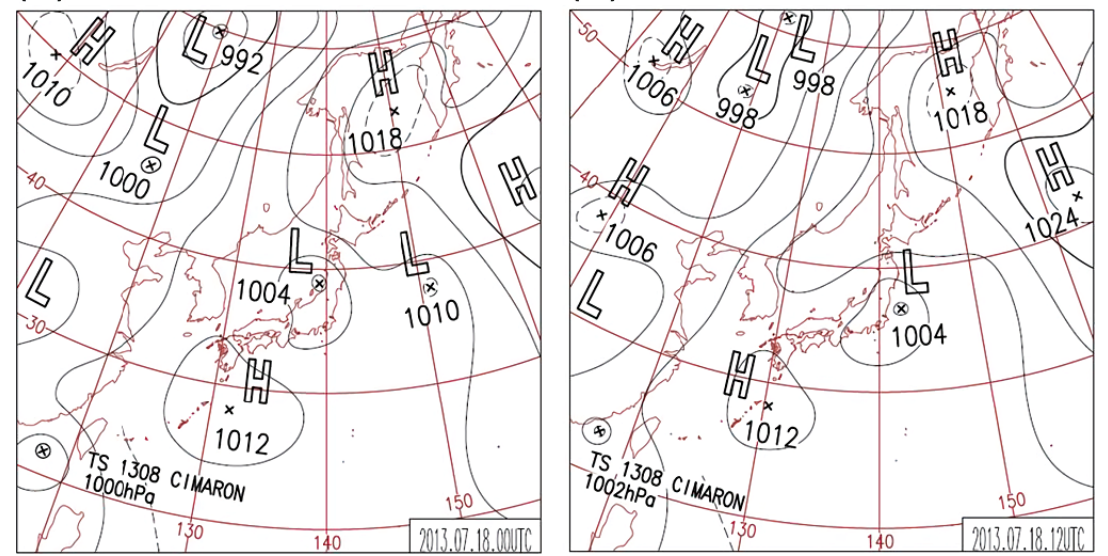

Fig. 15. Weather chart of (a) 09 JST and (b) 21 JST on July 18, 2013.

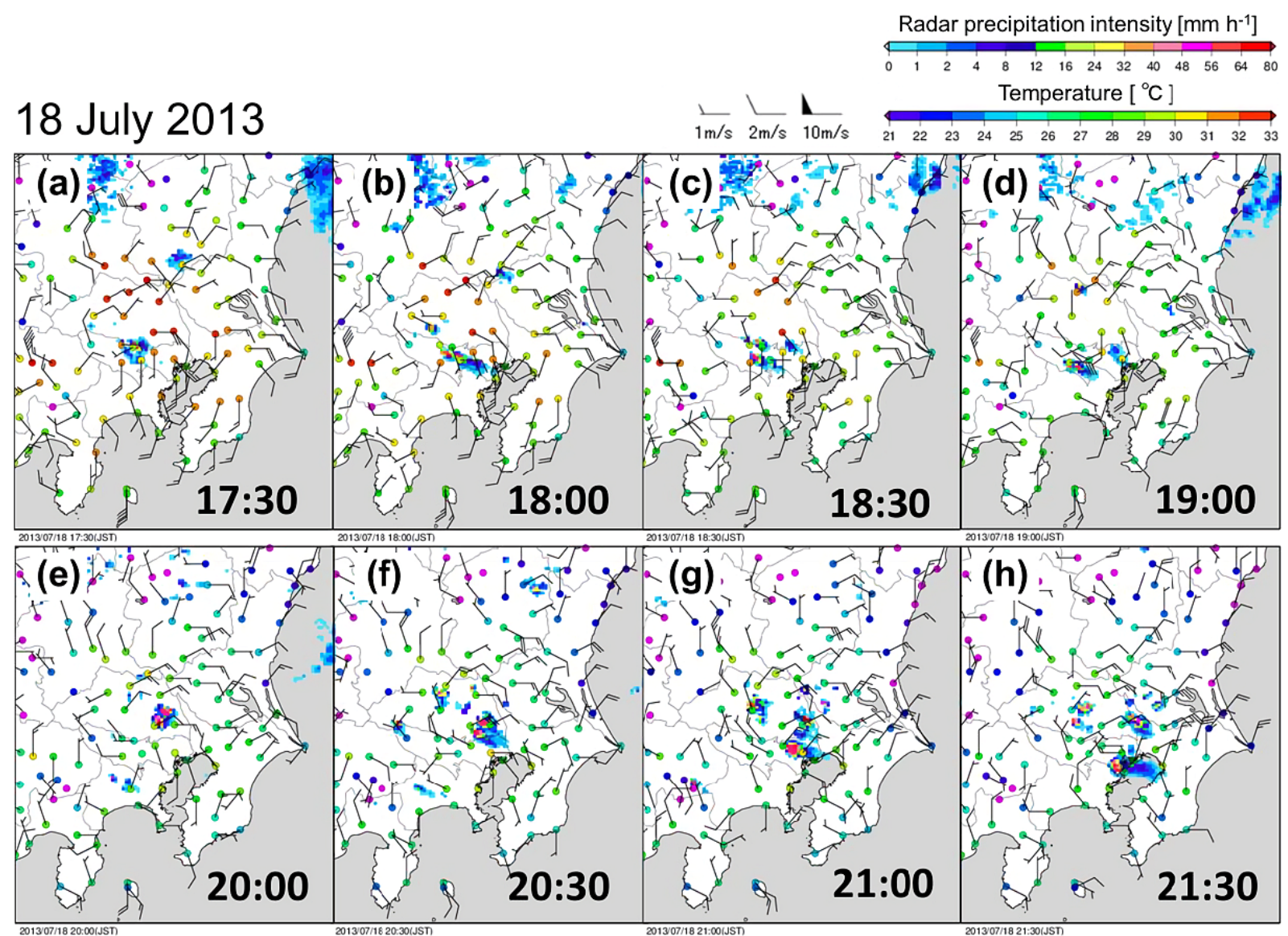

Fig. 16. Precipitation intensity (for the previous $5 \mathrm{~min}$ ) from the JMA radar network, surface winds, and temperatures at AMeDAS in the evening of July 18, 2013. 


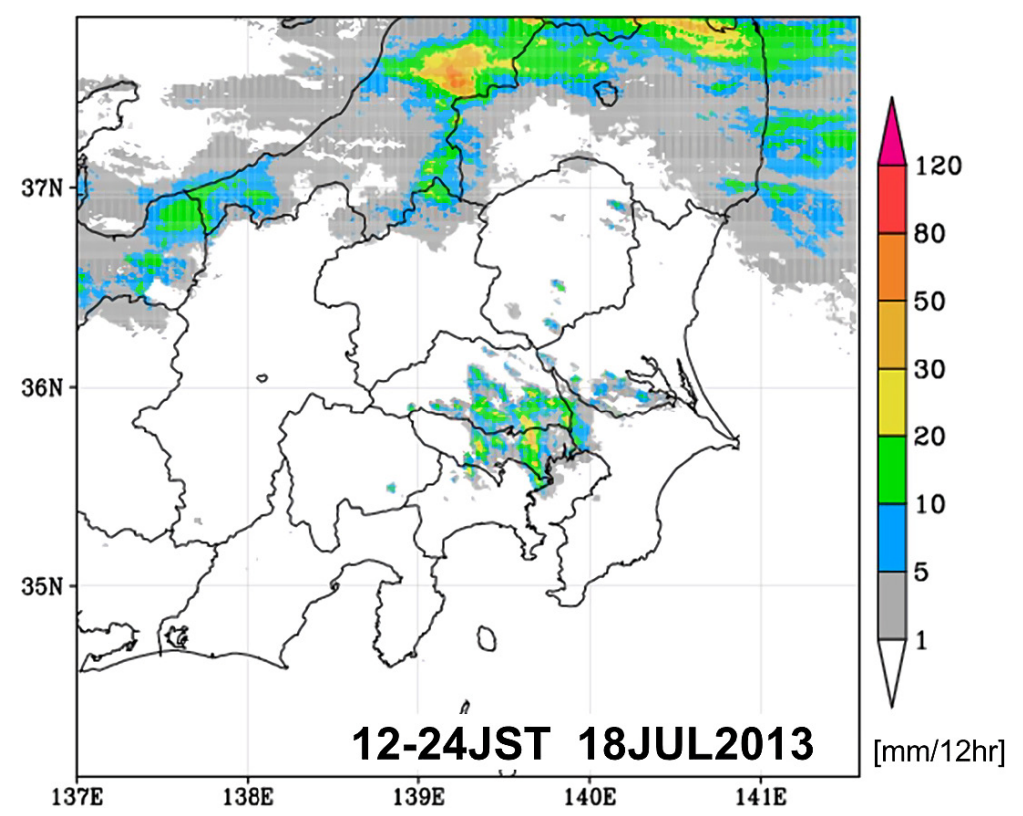

Fig. 17. Radar-rain gauge analyzed precipitation amount in the afternoon (12-24 JST) of July 18, 2013.

(a)

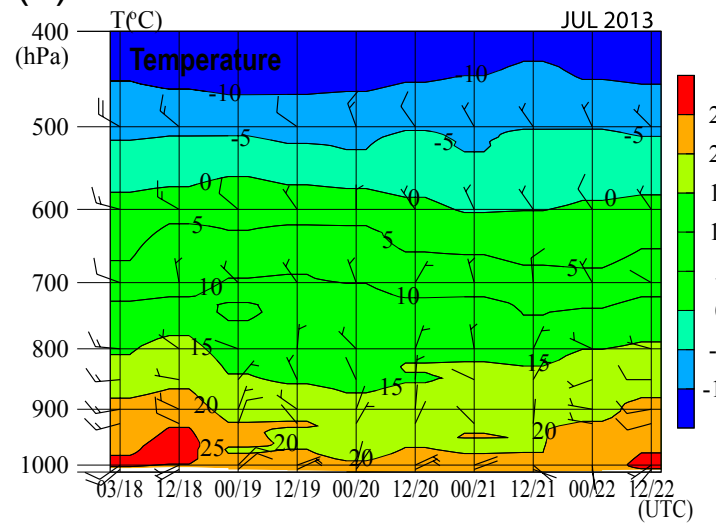

(b)

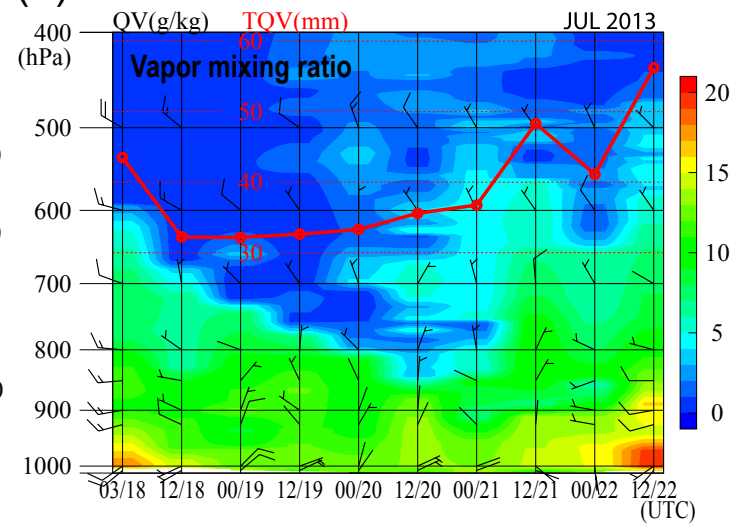

Fig. 18. Time-height cross sections of (a) temperature and (b) water vapor mixing ratio observed at Ryofu Maru from July $18-22,2013$. The thick red line in (b) indicates column-total precipitable water vapor amount in mm unit.

July 18 and 22, 2013 (Fig. 18). Associated heavy rainfalls occurred in Tokyo on July 18 and 23, 2013, and the warm and wet conditions observed offshore were clearly related to the formation of convective systems in the Kanto region.

In Case 2, easterly flow over the Kanto region developed more slowly than in Case 1 . As can be seen in Fig. 19, easterly surface winds became apparent around 14 JST on July 18. In the 14:30 JST sounding at Tsukuba, the easterly wind layer of approximately $600 \mathrm{~m}$ thick with a wind speed of less than $2 \mathrm{~m} \mathrm{~s}^{-1}$ was found (Fig. 20). At 17:30 JST, the wind speed of the easterly flow increased to $5 \mathrm{~m} \mathrm{~s}^{-1}$ at Tsukuba (Fig. 21). At Yokosuka, southerly winds were observed in the lower layer, as in Case 1, but the southerly wind layer was thinner, and the wind speed was lower.

A relatively large CAPE (more than $1000 \mathrm{~J} \mathrm{~kg}^{-1}$ ) was observed at 17:30 JST at all sites. Particularly, 


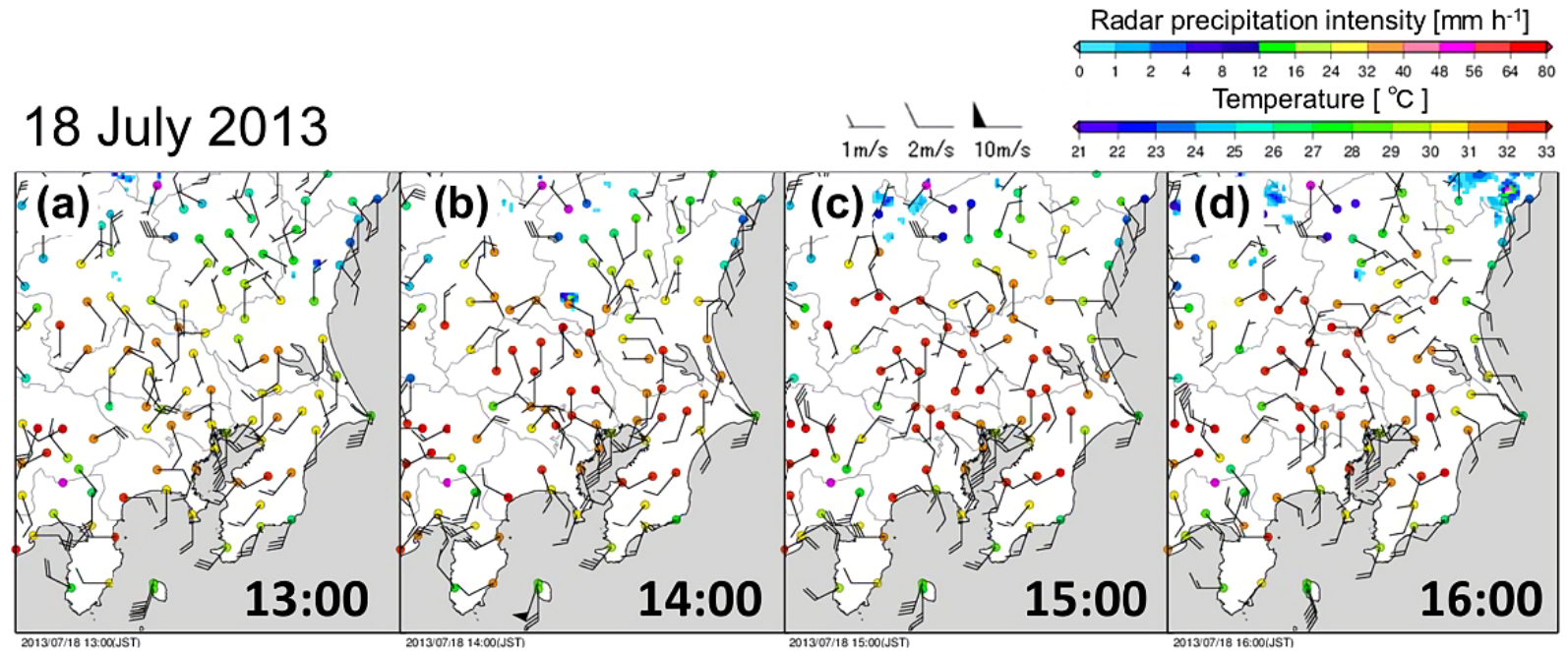

Fig. 19. Same as Fig. 16 but for 13-16 JST on July 18, 2013.

18 July $201314: 30$ JST
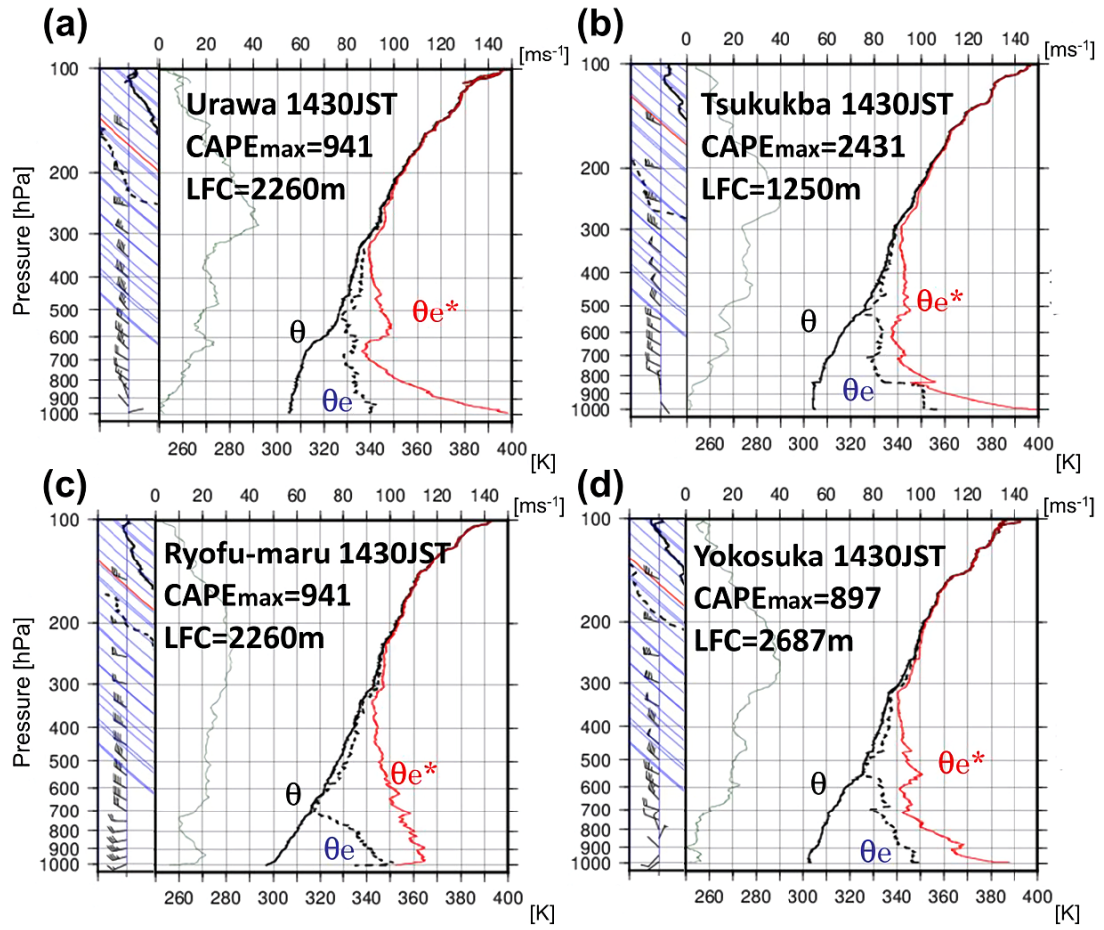

Fig. 20. Observed vertical profiles of potential temperature $(\theta), \operatorname{EPT}(\theta e)$, and $\operatorname{EPTS}\left(\theta e^{*}\right)$ at 14:30 JST on July 18, 2013, at (a) Urawa, (b) Tsukuba, (c) Ryofu Maru, and (d) Yokosuka.

at Tsukuba, the CAPE exceeded $3000 \mathrm{~J} \mathrm{~kg}^{-1}$ owing to the increase in the near-surface water vapor and EPT. Such an increase in the vapor amount was not observed at Urawa in the 17:30 JST sounding, and the CAPE there was smaller than in Tsukuba despite the higher surface air temperature. c. Results of modeling analysis for Case 2

The simulated amount and spatial distribution of afternoon precipitation (12-24 JST) show good agreement with observation at around Tokyo in the CRNT experiment (Fig. 22), but the onset of precipitation was delayed a few hours compared to the observation (Fig. 23). Simulated precipitation was exaggerated 


\section{July 2013 17:30JST}
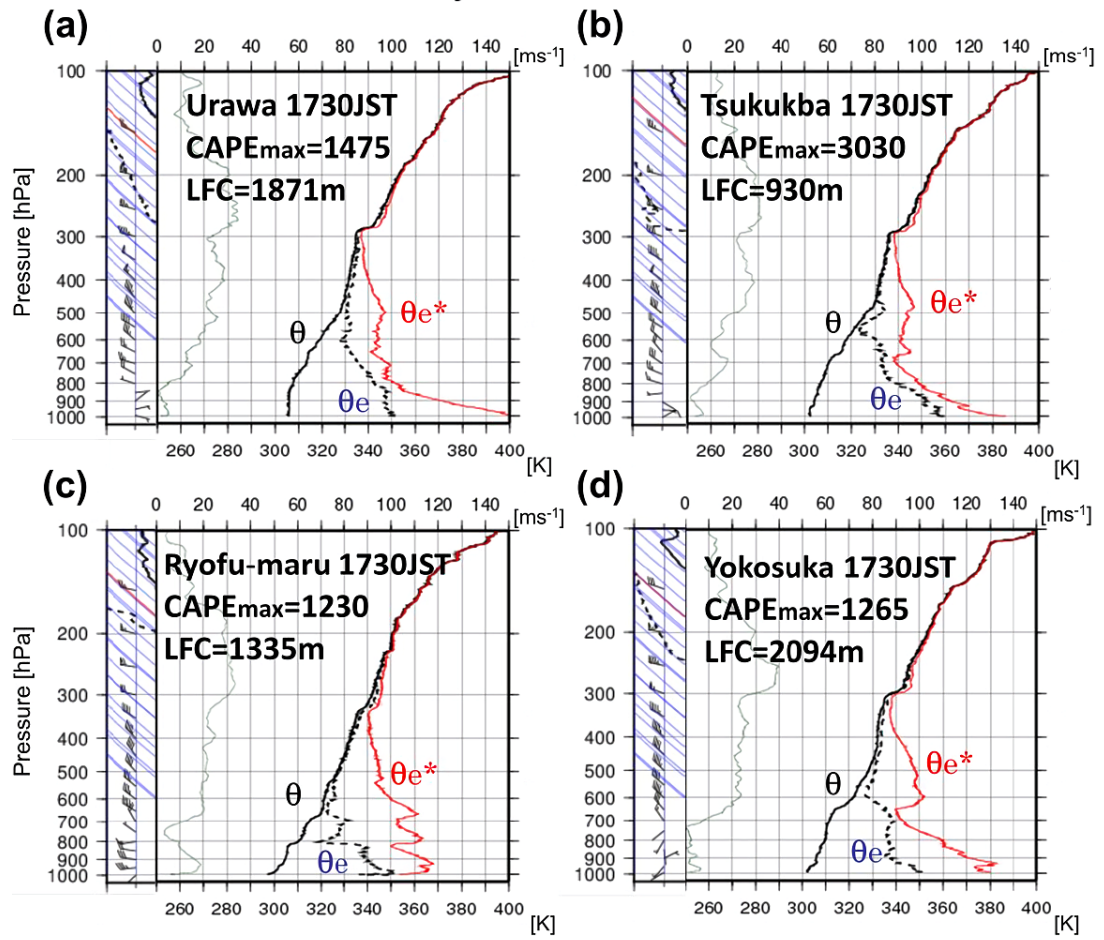

Fig. 21. Same as Fig. 20 but for 17:30 JST on July 18, 2013.

(a) CRNT

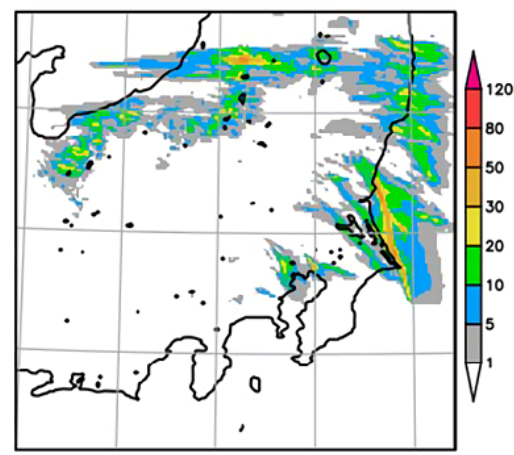

$[\mathrm{mm} / 12 \mathrm{hr}]$ (b) LURB

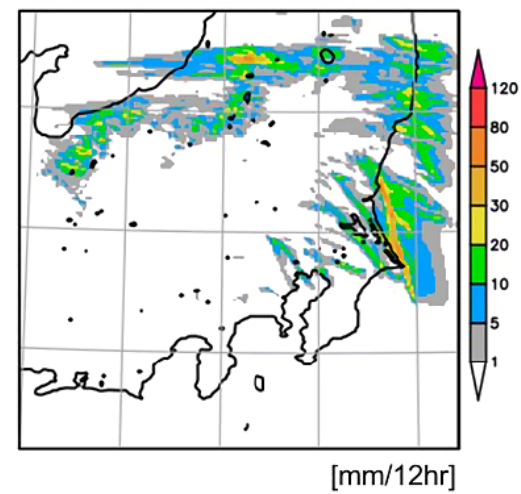

(c) CRNT-LURB

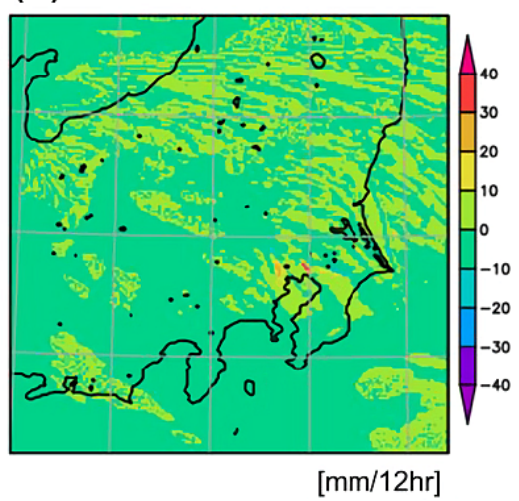

Fig. 22. Simulated precipitation amount in the afternoon (12-24 JST) of July 18, 2013, in (a) the CRNT experiment, (b) the LURB experiment, and (c) the difference between the experiments (CRNT-LURB).

along the eastern coast (too far south from the weak actual precipitation) probably because of the influence of the model boundary, but the anomaly appeared after 18 JST and little affected the development of the convective systems in the urban area. As shown in Fig. 24, simulated dew point temperatures at Tsukuba and Tokyo were underestimated in the afternoon before $18 \mathrm{JST}$, and the onset of easterly wind at Tsukuba was also delayed in this case. The formation of the evening convective systems was simulated by 20 JST at the leading edge of the southerly inflow slightly north of the central urban area. Subsequent rainfall was reasonably well simulated to the east of the central urban area at 21 JST in response to the easterly flow extension. The simulated surface convergence between the flow boundaries was weaker than in Case 1 (Fig. 25). 
(a)

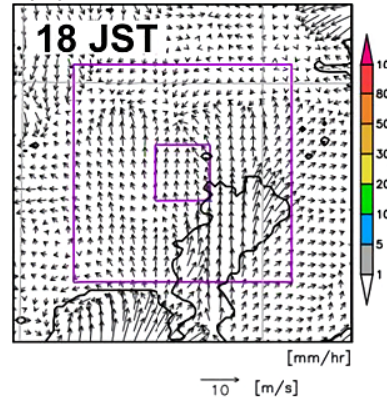

(e)

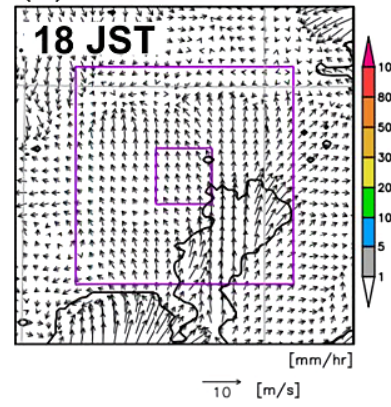

CRNT

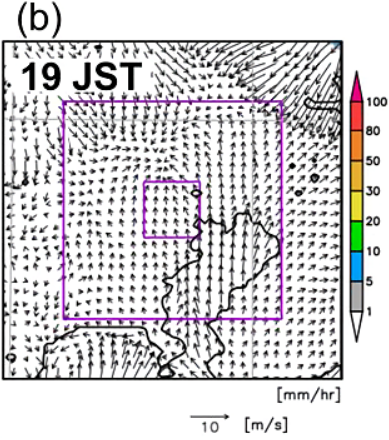

(c)

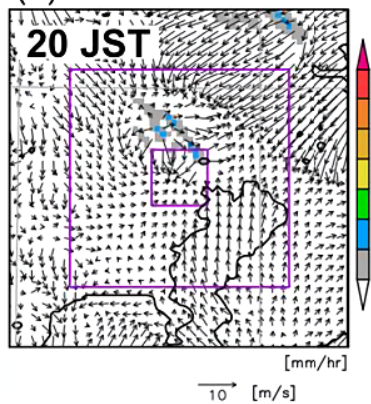

(d)

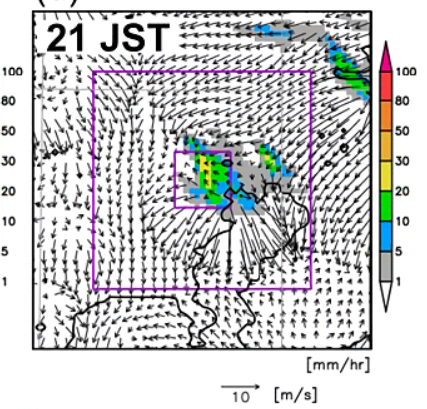

\section{LURB}
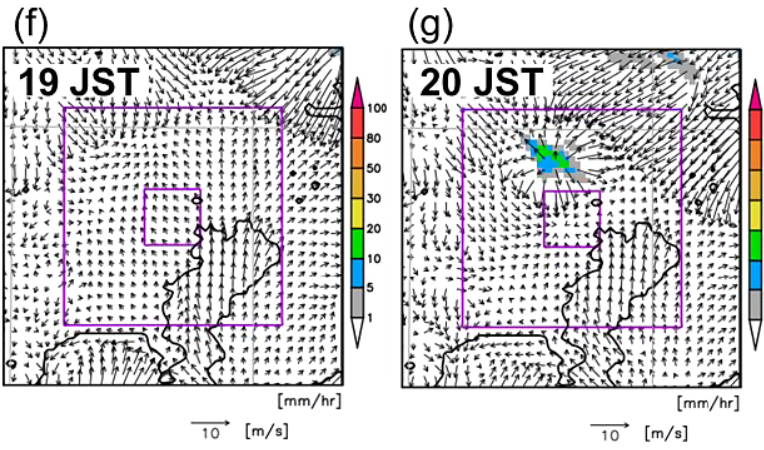

(h)

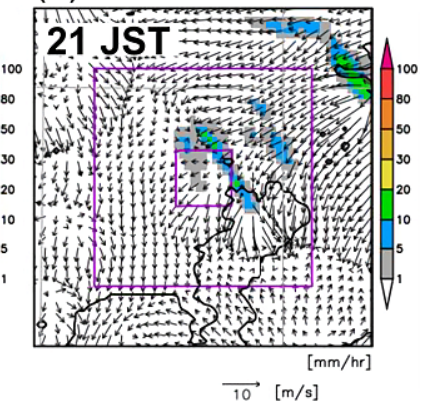

Fig. 23. Same as Fig. 11 but for the evening hours (18-21 JST) of July 18, 2013.

(a) Tsukuba 20130718

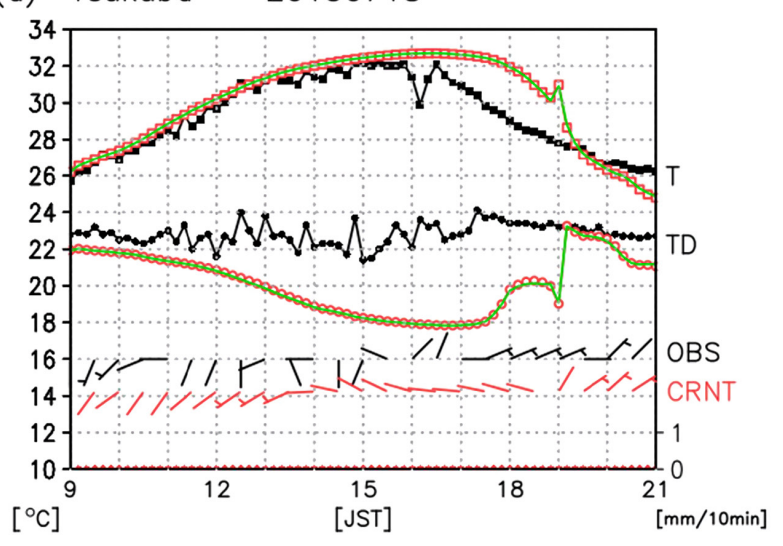

(b) Tokyo 20130718

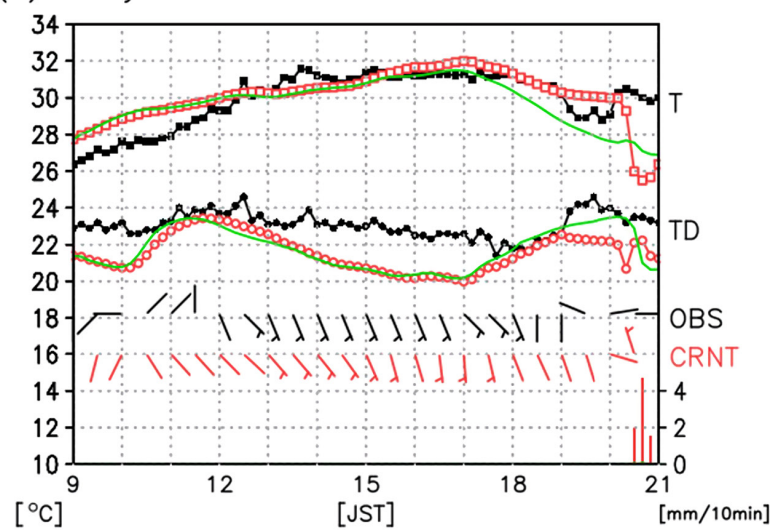

Fig. 24. Same as Fig. 9 but for (a) Tsukuba and (b) Tokyo on July 18, 2013.

Comparison of the CRNT and LURB experiments shows that the simulated precipitation amount was reduced in the LURB experiment, and the location of precipitation onset was changed between the two experiments; precipitation in the LURB experiment was simulated slightly north of that in the CRNT experiment downwind of the central urban area (Figs. 23c, g). Similar to Case 1, higher temperature and lower sea-level pressure in the urban area were simulated in the CRNT experiment before the onset of the precipitation (Fig. 26). The temperature anomaly greater than $2^{\circ} \mathrm{C}$ was found in a larger area than in 


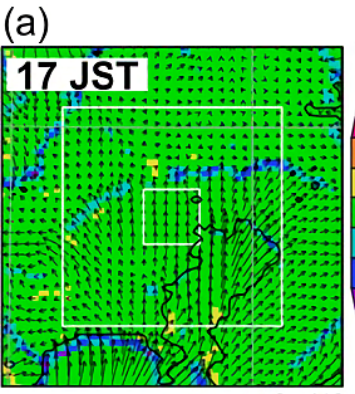

$\underset{10}{[\mathrm{~m} / \mathrm{s}]}$

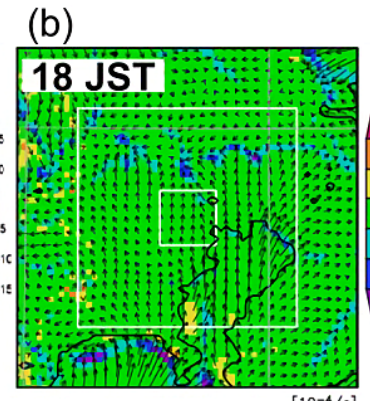

$\overrightarrow{10}[\mathrm{~m} / \mathrm{s}]$

\section{CRNT}

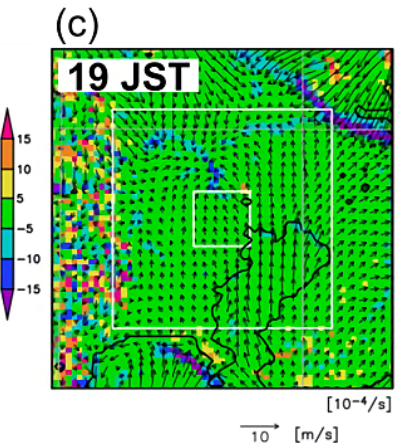

Fig. 25. Simulated divergence field (colors) and surface winds in the CRNT experiment at the lowest model level for (a) 17, (b) 18, (c) 19, and (d) 20 JST on July 18, 2013.

(a)

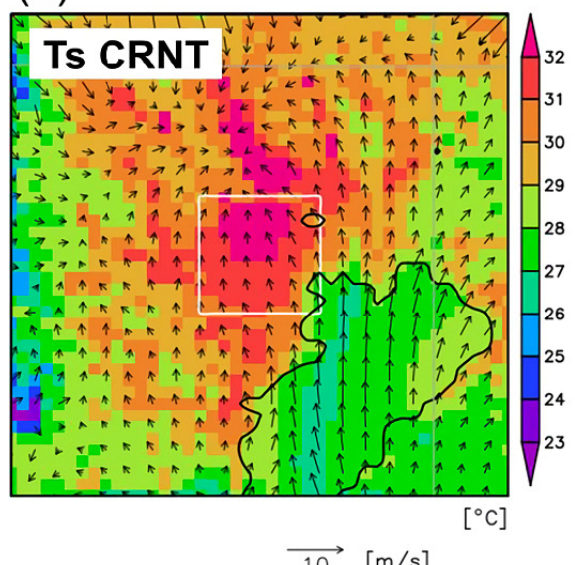

(c)

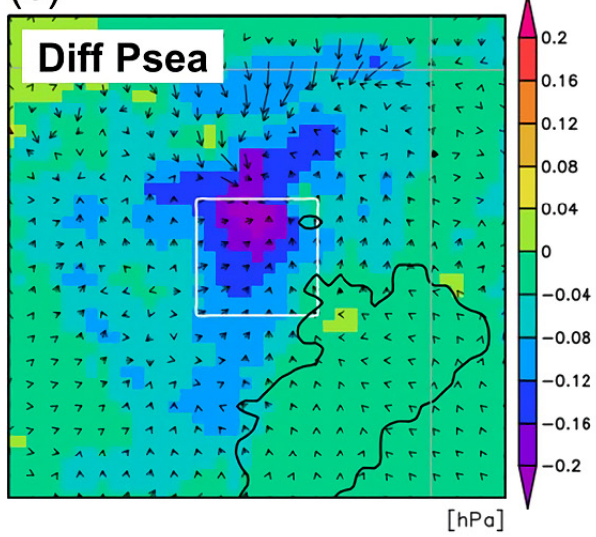

$\longrightarrow[\mathrm{m} / \mathrm{s}]$ (b)

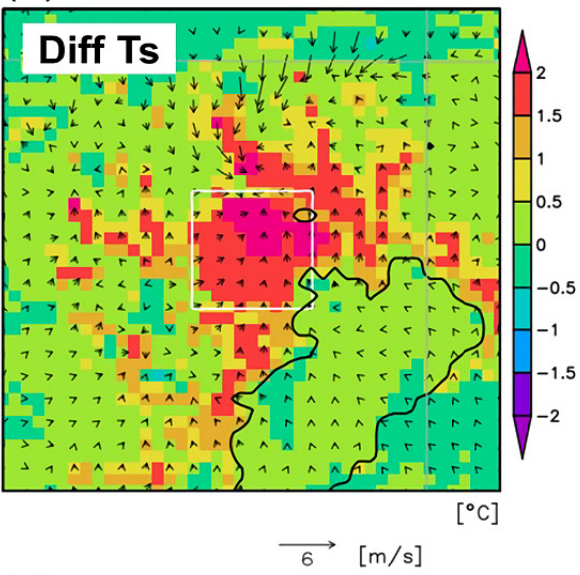

(d)

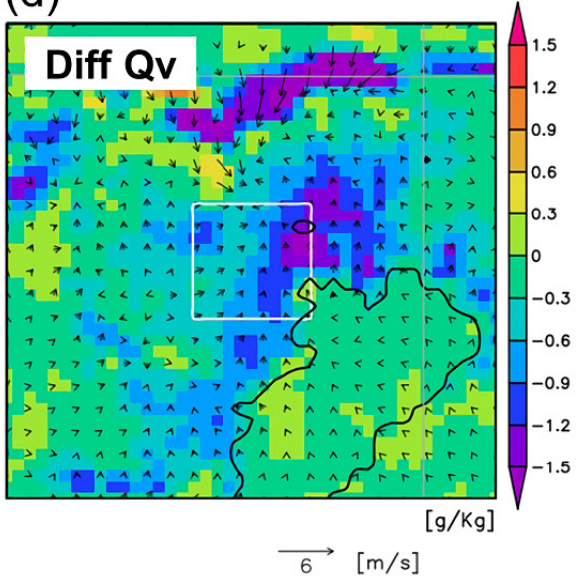

Fig. 26. Same as Fig. 13 but for 19 JST on July 18, 2013. 
Case 1 (in the central urban area and to its north), thus indicating that the urban heat island developed more widely before the onset of rainfall. On average, the water vapor mixing ratio was slightly decreased in the CRNT experiment. Figure 27 shows that the horizontal convergence was intensified in the CRNT experiment at the leading edge of the southerly inflow downwind of the central urban area, where the inland advance of the southerly inflow was delayed in association with the high temperature anomaly. The vertical cross sections also demonstrate that the low-level southerly inflow over the urban area reached higher altitudes in the CRNT experiment; thus, the horizontal convergence between the southerly and northerly flow was intensified north of the central urban area. Furthermore, upward motion intensified, and cloud water content increased, similar to that in Case 1 (Fig. 14).

(a)

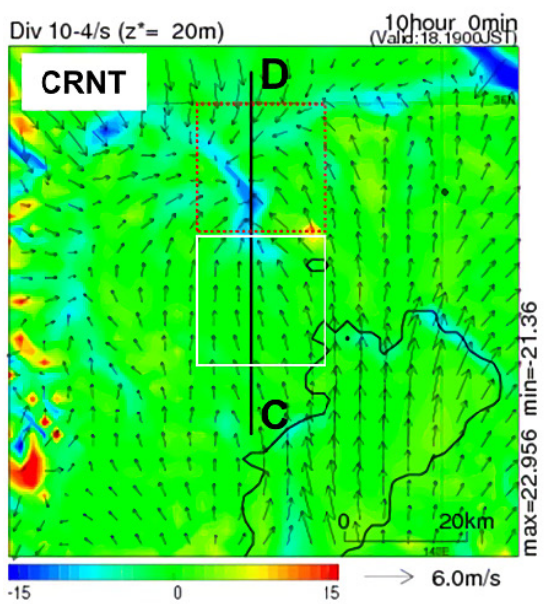

(c)

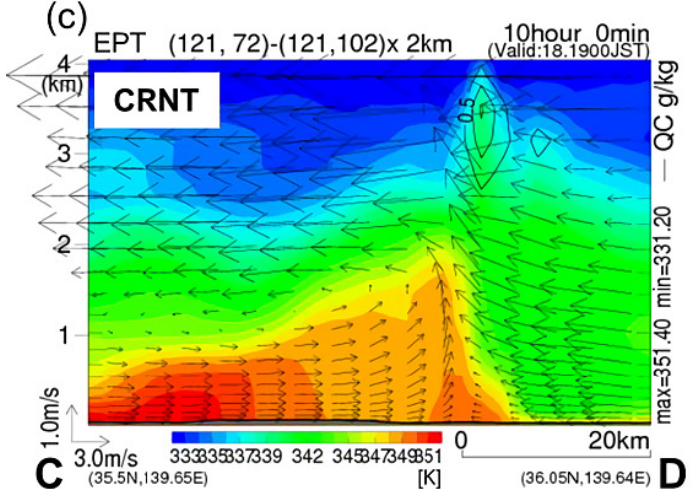

\section{Discussion}

\subsection{Comparison between Case 1 and Case 2}

In these two cases, thunderstorms occurred under the influence of synoptic disturbance, an approaching stationary front in Case 1, and a low pressure system passing over northern Japan in Case 2. This difference in the synoptic conditions partly explains the contrast of the storm activity (highly active in Case 1 and moderately active in Case 2). For the mesoscale wind characteristics, the synoptic conditions in both cases served the southerly prevailing wind in the lower atmosphere to the southern coastal area, as can be seen in the observation results at Yokosuka. In this area, daytime sunshine led to the formation of sea breeze and enhanced the southerly inflow. The longer duration of sunshine in Case 2 resulted in the further (b)

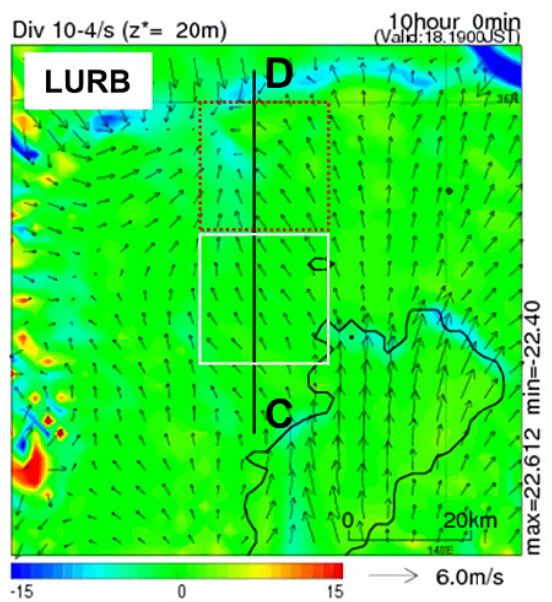

(d)

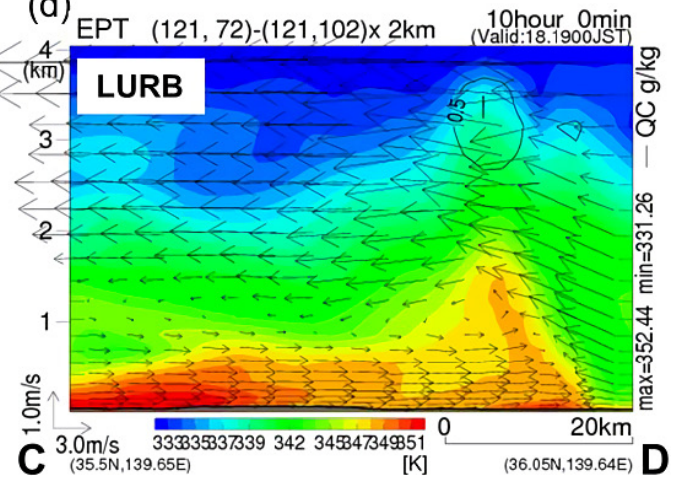

Fig. 27. Simulated horizontal divergence field (colors) at the lowest model level in (a) the CRNT and (b) LURB experiments at 19 JST on July 18, 2013. The white rectangle indicates the central urban area. The dotted red rectangle north of the central urban area is the domain for area averaging for Case 2 (see Fig. 29). The vertical cross sections along lines C-D show EPT (colors) and wind vectors in (c) the CRNT and (d) LURB experiment results at the same time. The black contours denote cloud water contents at $0.5 \mathrm{~g} \mathrm{~kg}^{-1}$ intervals. 
development of the southerly sea breeze until early evening.

In the eastern part of the Kanto Plain, easterly flow gradually extended westward to the urban area in both cases. In Case 1, coexisting easterly and southerly flows formed a well-developed E-S wind pattern and the convergence line in the early evening (Fig. 12). This case has many similarities to the Nerima heavy rain event (Seko et al. 2007; Kawabata et al. 2007) in the synoptic condition, mesoscale flow pattern, and severity and location of the storm. This case is also regarded a typical example of a severe storm that developed in the E-S wind pattern. In Case 2, the easterly flow developed more slowly and reached the Tokyo area in later hours than in Case 1, thus resulting in weaker convergence at the stage of convective cloud formation in this area (Figs. 25, 27).

Our results suggest that the evolution of easterly flow largely affected the convective cloud formation. Figure 28 shows that in Case 1, the easterly flow began earlier and formed a thicker layer than in Case 2. Although the formation process of the easterly flow is not well understood, its onset likely depended largely on synoptic forcing in these cases. The contributions of other possible formation factors, such as cold outflow from previously developed precipitation systems, should be examined in future research.

The stability indices and other environmental parameters derived from observations in Cases 1 and 2 are summarized in Table 3. Simulation results yield qualitatively similar contrast between cases. The stability indices in these cases were not very extreme compared to the evaluation results in previous studies (Hirahara and Mizuno 2000; Chuda and Niino 2005; Nomura and Takemi 2011). The CAPE and SSI in Case 2 exhibit slightly higher static instability than in Case 1. However, the observed CAPE was large only at Tsukuba (Figs. 20,21). The highly unstable area in Case 2 appeared to be limited to the leading edge of the easterly flow, and the precipitation in the urban area was initiated before the easterly flow reached the area. The lower level of free convection (LFC), the greater thickness of the easterly wind layer, and the formation of well-developed convergence lines in the E-S wind pattern may lead to a severe thunderstorm in Case 1. Furthermore, the lower humidity in the middle levels (700-500 $\mathrm{hPa}$ ) suppressed the development of the convective systems in Case 2 (Figs. 6, 21, 28).

\subsection{Comparison between the CRNT and LURB ex- periments}

In both Cases 1 and 2, the CRNT experiment simu- (a) 26 August 2011

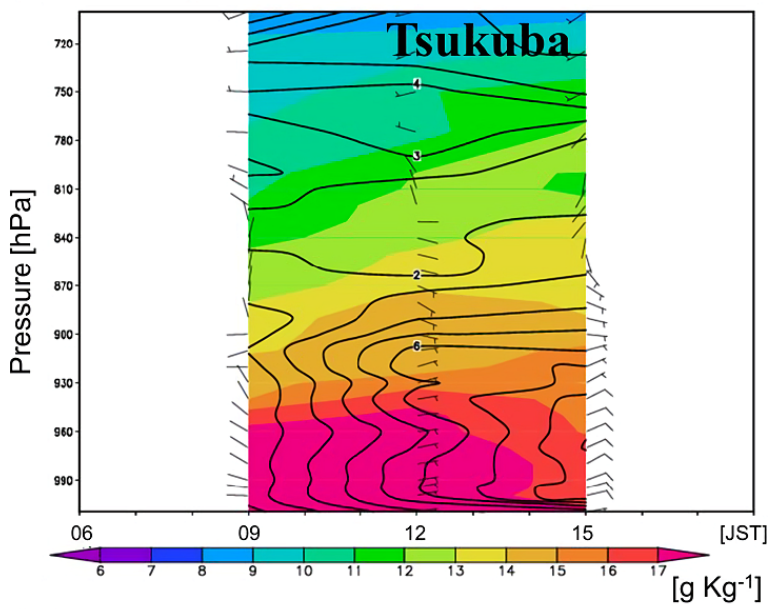

(b) 18 July 2013

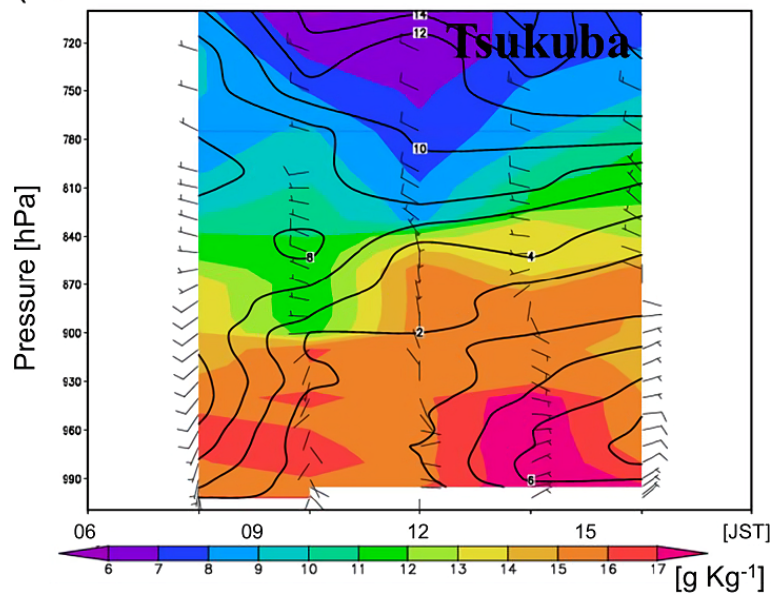

Fig. 28. Time-height cross section of the observed wind and moisture at Tsukuba on (a) August 26, 2011, and (b) July 18, 2013. Contours show the wind speed at $0.5 \mathrm{~m} \mathrm{~s}^{-1}$ intervals, and color shade shows vapor mixing ratio.

lated larger amounts of urban precipitation than in the LURB experiment. Table 4 indicates that simulated precipitation amounts from 12 to 24 JST in the central urban area were roughly doubled or more intensified in the CRNT experiment. In Case 2, more rainfall was also simulated in the surrounding reference urban domain (indicated by the outer box in Fig. 23). In this section, we discuss the cause of this difference in rainfall. Figure 29 compares the simulated vertical profiles of the potential temperature, EPT, saturated EPT (EPTS), and vertical velocity in the urban area during the cloud formation phase (one hour before the onset of rainfall) between the two experiments. The area av- 
Table 3. Stability indices and other parameters evaluated from observations in Cases 1 and 2 (maximum or minimum values).

\begin{tabular}{lcc}
\hline \multicolumn{1}{c}{ Index } & 26AUG2011 (Case 1) & 18JUL2013 (Case 2) \\
\hline CAPEmax $\left[\mathrm{J} \mathrm{Kg}^{-1}\right]$ & 2090 (Tsukuba) & 3030 (Tsukuba) \\
SSI & -1.1 (Tsukuba) & -1.3 (Tsukuba) \\
KI & 37 (Tsukuba) & 37 (Tsukuba) \\
$\theta \mathrm{e}(500 \mathrm{~m})-\theta \mathrm{e}^{*}(500 \mathrm{hPa})[\mathrm{K}]$ & -12 (Tsukuba) & -13 (Tsukuba) \\
$\mathrm{LFC}[\mathrm{m}]$ & 419 (Yokosuka) & 884 (Tsukuba) \\
Surface $\theta \mathrm{e}[\mathrm{K}]$ & 355 (Yokosuka) & 359 (Tsukuba) \\
Surface temperature $\left[{ }^{\circ} \mathrm{C}\right]$ & 32 (Tokyo) & 31 (Tokyo) \\
Southerly wind speed $\left[\mathrm{m} \mathrm{s}^{-1}\right]$ & 7.5 (Yokosuka) & 6.7 (Yokosuka) \\
Easterly wind speed $\left[\mathrm{m} \mathrm{s}^{-1}\right]$ & 7.0 (Tsukuba) & 6.9 (Tsukuba) \\
Thickness of southerly wind layer $[\mathrm{m}]$ & 696 (Yokosuka) & 598 (Yokosuka) \\
Thickness of easterly wind layer $[\mathrm{m}]$ & 1813 (Tsukuba) & 1130 (Tsukuba) \\
Relative humidity $(500 \mathrm{hPa}$ ) $[\%]$ & 75 (Yokosuka) & 38 (Tsukuba) \\
\hline
\end{tabular}

Table 4. Simulated quantities in the CRNT and LURB experiments estimated at 16 JST on August 26, 2011, for Case 1 and 19 JST on July 18, 2013, for Case 2 (except for precipitation amounts). The target domain is the central urban area for Case 1 and an area to the north of the central urban area (Fig. 27) for Case 2.

\begin{tabular}{|c|c|c|c|c|c|c|c|}
\hline \multirow{2}{*}{$\begin{array}{l}\text { Case } \\
\text { (date) }\end{array}$} & \multirow{2}{*}{ Variables } & \multicolumn{3}{|c|}{ Area-average } & \multicolumn{3}{|c|}{$\begin{array}{c}\text { Area-maximum } \\
\text { (Area-minimum for LFC) }\end{array}$} \\
\hline & & CRNT & LURB & $\begin{array}{l}\text { CRNT/ } \\
\text { LURB* }^{*}\end{array}$ & CRNT & LURB & $\begin{array}{l}\text { CRNT/ } \\
\text { LURB* }\end{array}$ \\
\hline \multirow{7}{*}{$\begin{array}{l}\text { Case } 1 \\
\text { (26 August } \\
2011)\end{array}$} & Precipitaion (12-24 JST) [mm] in central urban area & 44 & 20 & 2.20 & 156 & 79 & 1.97 \\
\hline & Precipitaion (12-24 JST) [mm] in reference urban area & 14 & 12 & 1.17 & 183 & 158 & 1.16 \\
\hline & CAPE $\left[\mathrm{J} \mathrm{kg}^{-1}\right]$ & 573 & 539 & 1.06 & 963 & 938 & 1.03 \\
\hline & $\mathrm{LFC}[\mathrm{m}]$ & 1335 & 1328 & 1.01 & 1073 & 1079 & 1.00 \\
\hline & Surface air temperature $\left[{ }^{\circ} \mathrm{C}\right]$ & 30.6 & 30.1 & $0.5^{*}$ & 31.9 & 31.3 & $0.6^{*}$ \\
\hline & Vapor mixing ratio $\left[\mathrm{g} \mathrm{kg}^{-1}\right]$ at $\mathrm{z}^{*}=10 \mathrm{~m}$ & 15.6 & 15.7 & 0.99 & 17.0 & 16.5 & 1.03 \\
\hline & Vertical velocity $\left[\mathrm{m} \mathrm{s}^{-1}\right]$ at $\mathrm{z}^{*}=1028 \mathrm{~m}$ & 0.35 & 0.24 & 1.44 & 2.15 & 1.75 & 1.23 \\
\hline \multirow{7}{*}{$\begin{array}{l}\text { Case } 2 \\
\text { (18 July } \\
2013)\end{array}$} & Precipitaion (12-24 JST) [mm] in central urban area & 8 & 2 & 4.00 & 26 & 13 & 2.00 \\
\hline & Precipitaion (12-24 JST) $[\mathrm{mm}]$ in reference urban area & 2 & 1 & 2.00 & 50 & 17 & 2.94 \\
\hline & CAPE $\left[\mathrm{J} \mathrm{kg}^{-1}\right]$ & 1056 & 1266 & 0.83 & 1674 & 1784 & 0.94 \\
\hline & $\mathrm{LFC}[\mathrm{m}]$ & 1775 & 1702 & 1.04 & 1544 & 1453 & 1.06 \\
\hline & Surface air temperature $\mathrm{Ts}\left[{ }^{\circ} \mathrm{C}\right]$ & 30.9 & 30.1 & $0.8^{*}$ & 32.9 & 31.2 & $1.7^{*}$ \\
\hline & Vapor mixing ratio $\mathrm{Qv}\left[\mathrm{g} \mathrm{kg}^{-1}\right]$ at $\mathrm{z}^{*}=10 \mathrm{~m}$ & 14.5 & 15.1 & 0.96 & 15.9 & 16.1 & 0.98 \\
\hline & Vertical velocity $\mathrm{W}\left[\mathrm{m} \mathrm{s}^{-1}\right]$ at $\mathrm{z}^{*}=1028 \mathrm{~m}$ & 0.29 & 0.12 & 2.35 & 0.99 & 0.94 & 1.05 \\
\hline
\end{tabular}

* CRNT-LURB for surface air temperature

erages were calculated over the area where differences between the two experiments were most apparent. In Case 1, the potential temperature was slightly (less than $1 \mathrm{~K}$ ) higher in the CRNT experiment than in the LURB experiment, up to $1500 \mathrm{~m}$ above the mean sea level. However, the EPT profiles differed little between the two experiments, thus reflecting the slightly smaller value of near-surface water vapor mixing ratio in the CRNT experiment (see Table 4). Greater ascending velocity was found in the CRNT experiment. Similar results were obtained in Case 2 (Fig. 29b).
The higher temperature in the CRNT experiment existed in a deeper layer from the surface level to more than $1500 \mathrm{~m}$ in height because of the more vigorous development of the heat island in this case (see Fig. 27 ), and the difference in vertical velocity between experiments was greater than in Case 1.

As a result, differences in simulated CAPE and LFC are quite small between the two experiments in these cases (Table 4). Although area-averaged CAPE was approximately $6 \%$ larger in the CRNT experiment in Case 1 , the change in the CAPE value occurred away 
(a) Case 1
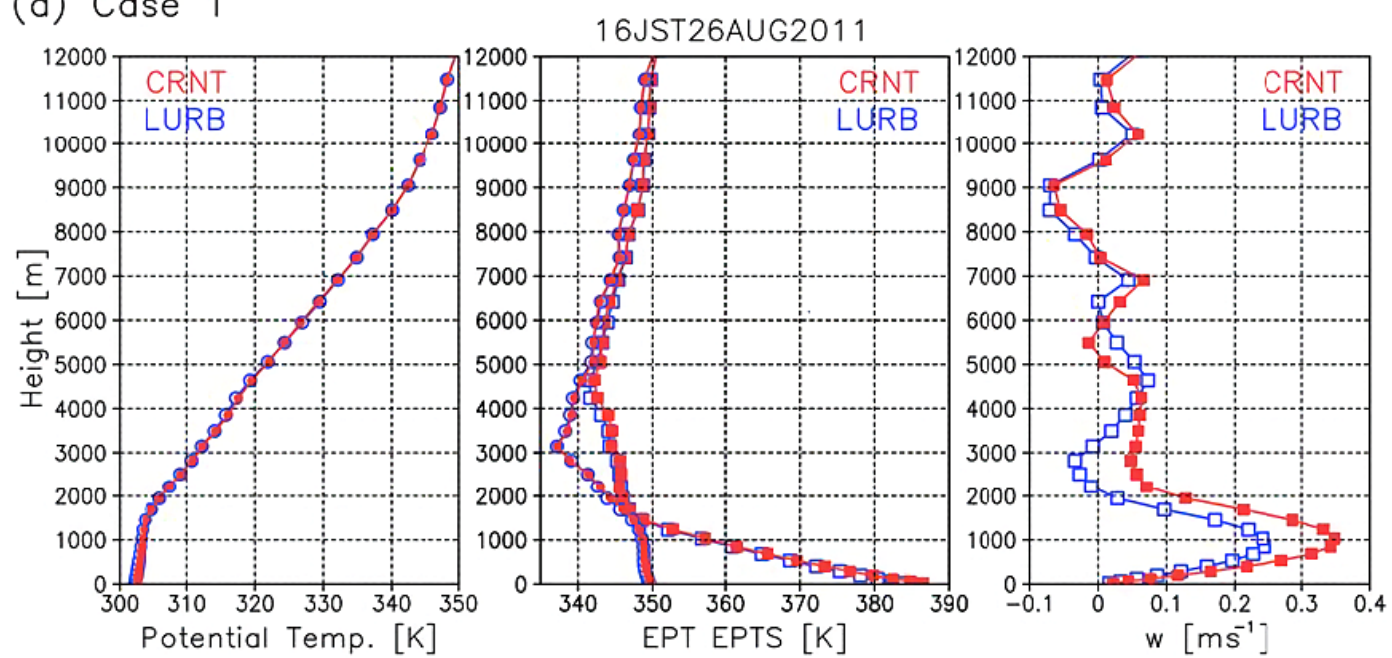

(b) Case 2
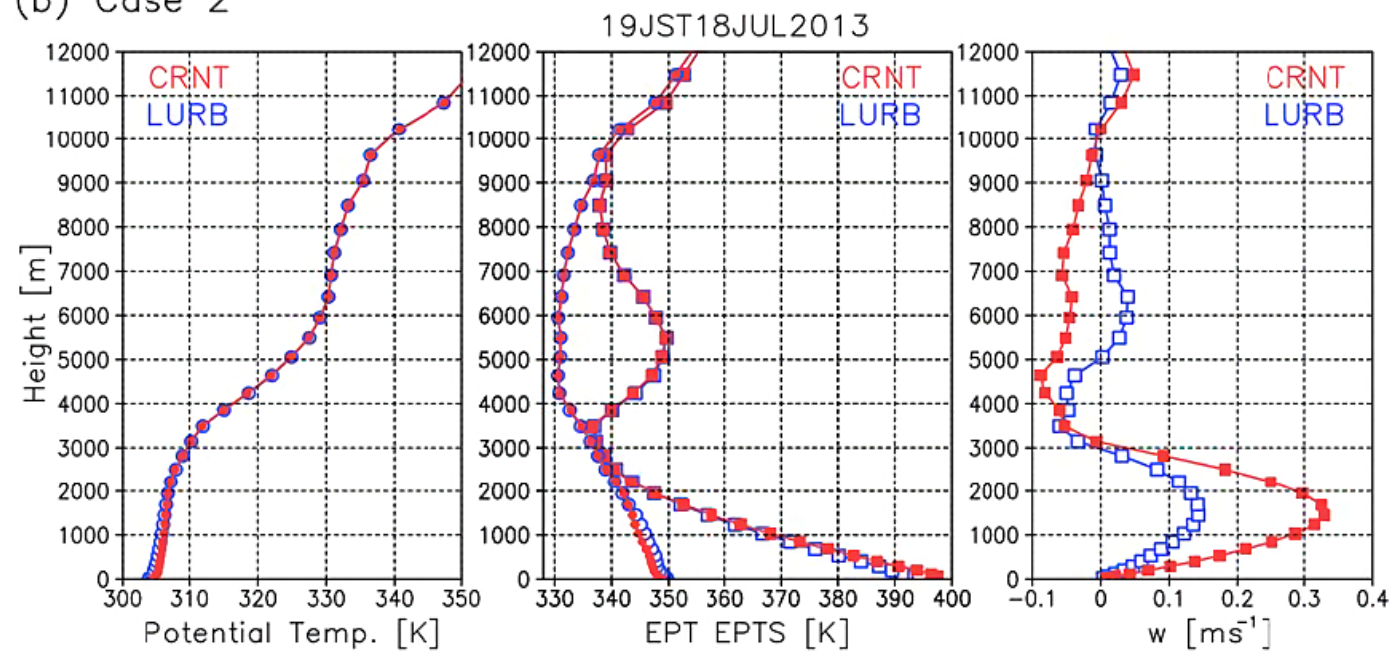

Fig. 29. Area-averaged vertical profiles up to $12000 \mathrm{~m}$ (roughly $200 \mathrm{hPa}$ ) for (a) 16 JST on August 26 and (b) 19 JST on July 18, 2013, showing (left) potential temperature, (center) EPT, EPTS, and (right) vertical velocity. The CRNT results are shown in red, and the LURB results are shown in blue. For (a), the area average is taken over the central urban area. For (b), the area average is taken over an area north of the central urban area (location in Fig. 27).

from the convergence line, and the area-maximum CAPE differed less than $3 \%$ between the two experiments. By contrast, the area-averaged vertical velocity in the CRNT experiment was $44 \%(135 \%)$ larger in Case 1 (Case 2) than in the LURB experiment at the height of $1028 \mathrm{~m}$ (below cloud level). This strongly suggests that the precipitation increase in the CRNT experiment was caused by the thermally induced change in circulation in the urban area and not by the change in static stability. The intensified convergence and ascending motion can increase the upward transport of the low-level moisture and consequently enhance convective cloud formation.

\section{Conclusions}

We investigated the mesoscale environment of the two contrasting heavy rainfall events in Tokyo during the TOMACS IOP. Case 1 (August 26, 2011) is one of the severest thunderstorms during the IOP, whereas Case 2 (July 18, 2013) shows heavy rainfall in a smaller area and has a lower precipitation amount than in Case 1. TOMACS radiosonde observations 
well captured the environmental conditions and their temporal variation in these heavy rain events. The results of observation and simulation in this study provide an improved understanding of the mesoscale environment of convective cloud formation. In Case 1 , convective systems developed in and around Tokyo along the convergence zone between southerly and easterly inflows. The lower LFC (less than $500 \mathrm{~m}$ ) and the thicker easterly flow layer (more than $1000 \mathrm{~m}$ ) of Case 1 than those in Case 2 characterized the mesoscale environment in Case 1. This case is regarded a typical example of a thunderstorm that developed in the E-S wind pattern. In Case 2, convective clouds first formed at the leading edge of the southerly flow over the central urban area, and the easterly inflow lead to the successive formation of convective systems. The easterly flow showed relatively large variability, and its evolution seems to be a key factor for the development of convective systems in the Kanto region.

We used comparative simulations to examine the mechanisms leading to urban-induced rainfall modification. In the CRNT experiment, current realistic urban surface conditions were assumed, whereas lessurbanized land surface conditions were given in the LURB experiment. Although the simulated onset of precipitation was delayed, the model results fairly represented the spatial distribution and amounts of rainfall. Greater amounts of precipitation in the CRNT experiment than in the LURB experiment were simulated in the central urban area, despite small differences in static stability. Comparison between the two experiments revealed that thermally induced changes in circulation occurred; thus, preexisting convergence and ascending motion in the urban area were intensified in the CRNT experiment. Resultant upward moisture transport can reasonably explain the enhancement of rainfall in the CRNT experiment.

This positive influence on rainfall enhancement due to urbanization and its mechanism agree well with the composite analysis of Seino et al. (2018) and the higher resolution (250 m horizontal grid interval) simulation for Case 1 (Bélair et al. 2018). However, this result does not imply that precipitation in the urban area is always enhanced because precipitation depends on various factors, and the urban impact on precipitation varies with meteorological conditions. Further examination under different synoptic and mesoscale conditions is needed to expand our understanding of the relationship between urbanization and heavy rainfall. To facilitate the prediction of heavy rainfall, it is important to improve the model representation of the near-surface water vapor amount, which is an issue to be addressed in future studies.

\section{Acknowledgments}

We are grateful to TOMACS members of MRI, Aerological Observatory, Ryofu Maru, Observation Department, Global Environment and Marine Department, Forecast Department of JMA, National Defense Academy, Japan Weather Association, National Institute of Information and Communications Technology, Ukima Water Reclamation Center, Chiba Institute of Science, and Okubo Water Filtration Plant for their cooperation in the radiosonde observations. We would like to thank two anonymous reviewers for their helpful comments. The stability indices calculation for observation data is made with the program package developed by O. Suzuki, K. Kusunoki, and H. Seko. This study was supported by the Japan Science and Technology Agency (JST) as part of the "Social System Reformation Program for Adaption to Climate Change" and by the Japan Society for the Promotion of Science Grants-in-Aid for Scientific Research (KAKENHI) (Grant No. 17H02964).

\section{References}

Aoyagi, T., and N. Seino, 2011: A square prism urban canopy scheme for the NHM and its evaluation on summer conditions in the Tokyo metropolitan area, Japan. J. Appl. Meteor. Climatol., 50, 1476-1496.

Bélair, S., S. Leroyer, N. Seino, L. Spacek, V. Souvanlasy, and D. Paquin-Ricard, 2018: Role and impact of the urban environment in a numerical forecast of an intense summertime precipitation event over Tokyo. $J$. Meteor. Soc. Japan, 96A, 77-94.

Beljaars, A. C. M., and A. A. M. Holtslag, 1991: Flux parameterization over land surfaces for atmospheric models. J. Appl. Meteor, 30, 327-341.

Chuda, T., and H. Niino, 2005: Climatology of environmental parameters for mesoscale convections in Japan. $J$. Meteor. Soc. Japan, 83, 391-408.

Fujibe, F., K. Sakagami, K. Chubachi, and K. Yamashita, 2002: Surface wind patterns in Tokyo in the preceding afternoon short-time heavy rainfall of midsummer days. Tenki, 49, 395-405 (in Japanese with English abstract).

Fujibe, F., H. Togawa, and M. Sakata, 2009: Long-term change and spatial anomaly of warm season afternoon precipitation in Tokyo. SOLA, 5, 17-20.

Hirahara, Y., and H. Mizuno, 2000: The availability of indices for the heavy rain forecast in Japan. J. Meteor. Res., 52, 125-142 (in Japanese).

Inamura, T., T. Izumi, and H. Matsuyama, 2011: Diagnostic study of the effects of a large city on heavy rainfall as revealed by an ensemble simulation: A Case study of central Tokyo, Japan. J. Appl. Meteor. Climatol., 50, 713-728. 
Ishihara, M., 2013: Radar echo population of thunderstorms and feasibility study on nowcasting of thunderstorminduced local heavy rainfalls. J. Disaster Res., 8, 133134.

Kawabata, T., H. Seko, K. Saito, T. Kuroda, K. Tamiya, T. Tsuyuki, Y. Honda, and Y. Wakazuki, 2007: An assimilation and forecasting experiment of the Nerima heavy rainfall with a cloud-resolving nonhydrostatic 4-dimensional variational data assimilation system. $J$. Meteor. Soc. Japan, 85, 255-276.

Kitagawa, H., 2000: Radiation processes. Sep. Vol. Annual report of NPD, 46, 16-31 (in Japanese).

Kusaka, H., K. Nawata, A. Suzuki-Parker, Y. Takane, and N. Furuhashi, 2014: Mechanism of precipitation increase with urbanization in Tokyo as revealed by ensemble climate simulations. J. Appl. Meteor. Climatol., 53, 824-839.

Matheson, M. A., and Y. Ashie, 2008: The effect of changes of urban surfaces on rainfall phenomenon as determined by a nonhydrostatic mesoscale model. $J$. Meteor. Soc. Japan, 86, 733-751.

Nakanishi, M., and H. Niino, 2006: An improved MellorYamada level-3 model: Its numerical stability and application to a regional prediction of advection fog. Bound.-Layer Meteor, 119, 397-407.

Nakatani, T., R. Misumi, Y. Shoji, K. Saito, H. Seko, N. Seino, S. Suzuki, Y. Shusse, T. Maesaka, and H. Sugawara, 2015: Tokyo metropolitan area convection study for extreme weather resilient cities. Bull. Amer. Meteor. Soc., 96, ES123-ES126.

Nomura, S., and T. Takemi, 2011: Environmental stability for afternoon rain events in the Kanto Plain in summer. SOLA, 7, 9-12.

Saito, K., T. Fujita, Y. Yamada, J. Ishida, Y. Kumagai, K. Aranami, S. Ohmori, R. Nagasawa, S. Kumagai, C. Muroi, T. Kato, H. Eito, and Y. Yamazaki, 2006: The operational JMA nonhydrostatic mesoscale model. Mon. Wea. Rev., 134, 1266-1298.

Saito, K., M. Kunii, and K. Araki, 2018: Cloud resolving simulation of a local heavy rainfall event on 26 August 2011 observed in TOMACS. J. Meteor. Soc. Japan, 96A, 175-199.

Saito, S., K. Kusunoki, and H. Y. Inoue, 2013: A case study of the merging of two misocyclones in the TOMACS field campaign area of Tokyo on 26 August 2011. SOLA, 9, 153-156.

Sakurai, N., S. Shimizu, Y. Shusse, S. Suzuki, T. Maesaka, K. Kieda, and K. Iwanami, 2015: Relationships between updraft characteristics and cloud-to-ground lightning activity in warm-season convective storms in the Kanto region, Japan. SOLA, 11, 177-180.

Seino, N., T. Nakano, Y. Noto, and K. Oono, 2014: Validation of aerological observation simulation program and application to radiosonde observations in TOMACS. Pap. Meteor. Geophys., 65, 1-14 (in Japanese with English abstract and figures).

Seino, N., T. Aoyagi, and H. Tsuguti, 2018: Numerical simu- lation of urban influence on summertime precipitation in Tokyo-How does urban temperature rise affect precipitation? Urban Climate, 23, 8-35.

Seko, H., Y. Shoji, and F. Fujibe, 2007: Evolution and airflow structure of a Kanto thunderstorm on 21 July 1999 (the Nerima heavy rainfall event). J. Meteor. Soc. Japan, 85, 455-477.

Senoo, H., M. Kanda, T. Kinouchi, and A. Hagishima, 2004: Estimation of anthropogenic heat and vapour emission, and the impact on local meteorology. Ann. J. Hydraul. Eng., 48, 160-174 (in Japanese with English abstract).

Shepherd, J. M., 2013: Impacts of Urbanization on precipitation and storms: Physical insights and vulnerabilities. Climate vulnerability: Understanding and Addressing Threats to Essential Resources. Vol. 5, Pielke, R. (ed.), Elsevier Inc., Academic Press, 109-125.

Shimoju, R., M. Nakayoshi, and M. Kanda, 2010: Case analyses of localized heavy rain in Kanto considering urban parameters. Ann. J. Hydraul. Eng., 54, 349-354 (in Japanese with English abstract).

Shoji, Y., 2018: Introduction: dense meteorological observations in TOMACS and outline of Part 1. Observation, prediction, and information communication for extreme weather in urban area. Kishou Kenkyu Note, 236 pp (in Japanese).

Souma, K., K. Tanaka, T. Suetsugi, K. Sunada, K. Tsuboki, T. Shinoda, Y. Wang, A. Sakakibara, K. Hasegawa, Q. Moteki, and E. Nakakita, 2013: A comparison between the effects of artificial land cover and anthropogenic heat on a localized heavy rain event in 2008 in Zoshigaya, Tokyo, Japan. J. Geophys. Res., 118, 11600-11610.

Sugawara, H., H. Aiso, R. Oda, and N. Seino, 2015: Comparison of daytime air heating amount between city and surrounding areas. J. Heat Isl. Inst. Int., 10, 1-5 (in Japanese with English abstract).

Sugawara, H., R. Oda, and N. Seino, 2018: Urban thermal influence on the precipitation system. J. Meteor. Soc. Japan, 96A, 67-76.

Tokyo Regional Headquarters, JMA, 2011: Meteorological report on 26-27 August Heisei 23rd heavy rainfall (in Japanese). [Available at http://www.jma-net.go.jp/ tokyo/sub_index/bosai/disaster/20110826/20110826. html.]

Tsuguti, T., and T. Kato, 2014: Objective extraction of heavy rainfall events and statistical analysis on their characteristic features. Tenki, 61, 455-468 (in Japanese with English abstract).

Yabu, S., S. Murai, and H. Kitagawa, 2005: Clear sky radiation scheme. Sep. Vol. Annual Report of NPD, 51, 5364 (in Japanese).

Yamauchi, H., H. Niino, O. Suzuki, Y. Shoji, E. Sato, A. Adachi, and W. Mashiko, 2013: Vertical structure of the Tsukuba F3 tornado on 6 May 2012 as revealed by a polarimetric radar. Proceedings of the 36th Conference on Radar Meteorology, Breckenridge, USA. 